\title{
Investigating Decadal Changes of Multiple Hydrological Products and Land-Cover Changes in the Mediterranean Region for 2009-2018
}

\author{
Wenzhao $\mathrm{Li}^{1} \cdot$ Sachi Perera${ }^{2} \cdot$ Erik Linstead $^{3} \cdot$ Rejoice Thomas $^{4} \cdot$ Hesham El-Askary ${ }^{1,4,5}$ (D) Thomas Piechota ${ }^{1}$. \\ Daniele Struppa ${ }^{1}$
}

Received: 15 December 2020 / Accepted: 15 March 2021 / Published online: 30 March 2021

(c) The Author(s) 2021

\begin{abstract}
Land-cover change is a critical concern due to its climatic, ecological, and socioeconomic consequences. In this study, we used multiple variables including precipitation, vegetation index, surface soil moisture, and evapotranspiration obtained from different satellite sources to study their association with land-cover changes in the Mediterranean region. Both observational and modeling data were used for climatology and correlation analysis. Famine Early Warning Systems Network (FEWS NET) Land Data Assimilation System (FLDAS) and Global Land Data Assimilation System (GLDAS) were used to extract surface soil moisture and evapotranspiration data. Intercomparing the results of FLDAS and GLDAS suggested that FLDAS data had better accuracy compared to GLDAS for its better coherence with observational data. Climate Hazards Group Infra-Red Precipitation with Station Data (version 2.0 final) (CHIRPS Pentad) were used to extract precipitation data while Moderate Resolution Imaging Spectroradiometer (MODIS) products were used to extract the vegetation indices used in this study. The land-cover change detection was demonstrated during the 2009-2018 period using MODIS Land-Cover data. Some of the barren and crop lands in Euphrates-Tigris and Algeria have converted to low-vegetated shrublands over the time, while shrublands and barren areas in Egypt's southwestern Delta region became grasslands. These observations were well explained by changing trends of hydrological variables which showed that precipitation and soil moisture had higher values in the countries located to the east of the Mediterranean region compared to the ones on the west. For evapotranspiration, the countries in the north had lower values except for countries in Europe such as Bosnia, Romania, Slovenia, and countries in Africa such as Egypt and Libya. The enhanced vegetation index appeared to be decreasing from north to south, with countries in the north such as Germany, Romania, and Czechia having higher values, while countries in the south such as Libya, Egypt, and Iraq having lower trends. Time series analysis for selected countries was also done to understand the change in hydrological parameters, including Enhanced Vegetation Index, evapotranspiration, and soil moisture, which showed alternating drop and rise as well as stagnant values for different parameters in each country.
\end{abstract}

Keywords Land-cover change $\cdot$ Mediterranean region $\cdot$ Hydrological variables $\cdot$ FLDAS $\cdot$ GLDAS

Hesham El-Askary

elaskary@chapman.edu

1 Schmid College of Science and Technology, Chapman University, Orange, CA 92866, USA

2 Computational and Data Sciences Graduate Program, Schmid College of Science and Technology, Chapman University, Orange, CA 92866, USA

3 Fowler School of Engineering, Chapman University, Orange, CA 92866, USA
4 Center of Excellence in Earth Systems Modeling and Observations, Chapman University, Orange, CA 92866, USA

5 Department of Environmental Sciences, Faculty of Science, Alexandria University, Moharem Bek, Alexandria 21522, Egypt 


\section{Introduction}

Land cover is an important factor in maintaining environmental, climatic, ecological, and economical stability in a region, and tracking its changes is very important for planning for different fields of study in the Earth Sciences, especially climate changes. For example, the amount of solar energy reflected from a land surface can change the local surface energy balances (Dickinson 1983; Feddema et al. 2005; Vargo et al. 2013). Changes in land cover can also impact the properties of absorbed energy that is released as heat as well as the energy that is dissipated through evaporation (Vargo et al. 2013). Land-cover changes mainly affects the environment through biogeochemical and biogeophysical processes (Feddema et al. 2005) (Fig. 1). The biogeochemical effects of land-cover change change the concentration of greenhouse gases in the atmosphere through carbon storage or release and also affects long (short) wave radiation, while the biogeophysical effects of land-cover change changes the physical characteristics of the land surface (such as surface albedo, surface emissivity, surface roughness, evapotranspiration, etc.), which in turn affects the distribution of surface energy and the circulation of water, which has an important impact on the climate (Pielke et al. 2002). In particular, changes in the surface albedo change the surface's absorption of solar short-wave radiation and changes the leaf area index (vegetation coverage), which affects evapotranspiration and leads to redistribution of surface energy. Surface Albedo differs with land type wherein the albedo of a forested land is typically lower than that of a cultivated land. In polar regions, the extra absorption of shortwave radiation as ice melts renders the surface less reflective. There are studies which have shown how surface albedo impacts climate change like a study by Betts which concluded that the positive forcing induced by decreases in albedo can offset the negative forcing, that is expected from carbon sequestration in boreal forest areas, and thus, some high-latitude

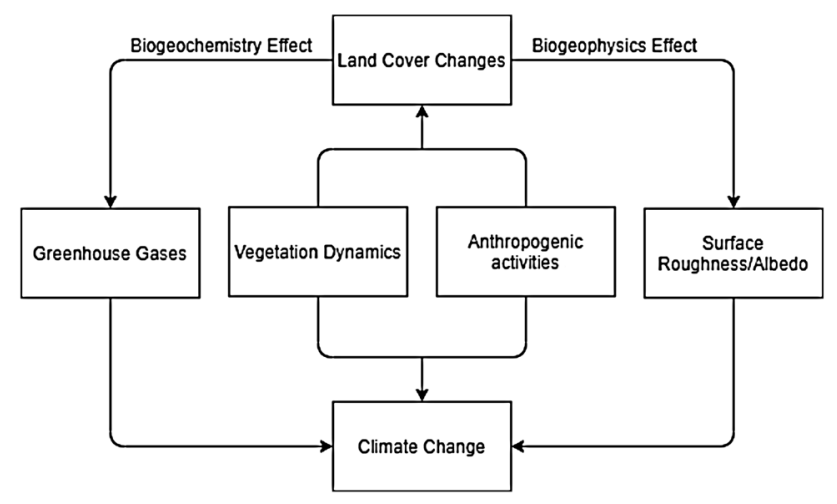

Fig. 1 Flowchart for the effect of land-cover changes on environment forestation activities may therefore increase climate change, rather than mitigating it as intended (Betts 2000). Another study by Winton also showed surface albedo feedback to be a contributing factor in the simulated Arctic amplification and its intermodel variation (Winton 2006). Apart from surface albedo and evapotranspiration, land cover also affects precipitation in a region. A study conducted in the Amazon basin by Bagley et al. displayed that drought conditions brought a decrease in dry season heat flux, while an increase in dry season moisture recycling as well as deforestation impacts on surface conditions. The study concluded that land-cover change is capable of reducing precipitation and increasing the amplitude of droughts in the Amazon basin (Bagley et al. 2014). Yet, another study by Perugini et al. concluded that there is a strong regional effect on temperature and precipitation and a minor global impact on temperature due to largescale land-cover changes (Perugini et al. 2017). Surface soil moisture is also one of the important biophysical parameters affected by land-cover change. A study by Jiang et al. in the midwestern part of United States of America compared various land-cover types and their corresponding changes to the change in parameters like land surface temperature (LST), fractional vegetation cover, Normalized Difference Water Index (NDWI), impervious fractions evaporative fraction, and soil moisture. The results from the study showed that areas with low temperature, dense vegetation cover, and high surface moisture conditions were affected by the land-cover chages more than areas with higher temperature, sparse vegetation cover, and low surface moisture conditions (Jiang et al. 2015). Large-scale events namely El Niño and La Niña are known to affect western US, namely California and Nile river basin countries (Le et al. 2017, 2020). Landcover change also has an ecological and socioeconomic impact. Changing the natural vegetation to agriculture land would impact the energy absorption and reflection. Also, agricultural expansion would be good on a short-term basis, but for long term, the quality of land after being exploited would come into play which could change the dynamics of economic statbility in a region. Thus, tracking land-cover changes would help in efficient land-use planning which would in turn increase productivity from energy resources. Remote sensing and GIS frameworks, such as image analysis, are combined with contemporary information extraction approaches to detect vegetation changes (Sluiter 2005; Li et al. 2019a, b, c) as well as soil assessment (Whitney et al. 2018). Apart from detecting vegetation changes, remote sensing and GIS processes have been extensively used in land-use/land-cover (LULC) classification (Rwanga and Ndambuki 2017) and LULC change detection (Kafi et al. 2014), as well. Therefore, remote sensing and GIS processes are cost-effective and flexible with monitoring, storing, analyzing, and displaying land-cover changes. 
The Mediterranean region is amongst the most arid/semiarid areas in the world, due to its warm weather throughout the year. It is also known to have rich biodiversity, diverse vegetation, and specific regional features. Over the past years, the Mediterranean region is facing complex unanticipated and gradual land-cover changes (Lasanta and VicenteSerrano 2012). The Mediterranean and its adjacent regions form an extremely fragile ecological system and sensitive to human activities in terms of marine productivity ( $\mathrm{Li}$ et al. 2017, 2018), air quality (El-Askary et al. 2019; El-Nadry et al. 2019; Li et al. 2019a), and land and coastal environment (Li et al. 2019b, c; Sardi et al. 2020; Serra et al. 2008). It is also found that major land-cover changes in this region are due to urban developments, industrial activities, land expansions, and, due to the forest fires, global warming and droughts (Lasanta and Vicente-Serrano 2012; Mahmoud and Alazba 2015).

Hydrological variables such as precipitation, enhanced vegetation index (EVI), evapotranspiration (ET), and soil moisture are suggested to be prominent indicators to detect and explain land-cover and land-use changes ( $\mathrm{Li}$ et al. 2020a, b; Maneja et al. 2020a, b). The main objective of the current study is to focus on detecting land-cover changes from 2009 to 2018 in the Mediterranean region. This will take place by analyzing 10 years of data from the aforementioned indicators and look into their mean distributions, correlations, and interactions amongst them. To achieve our objectives, model data from the Famine Early Warning Systems Network (FEWS NET) Land Data Assimilation System (FLDAS) and the Global Land Data Assimilation System (GLDAS) will be employed and utilized against remote-sensing observations for data validation and for possible integration. We have used such datasets to investigate land-cover changes in drylands where drier trends were observed in the south of Africa and the east of Australia as compared to wetter trends in Mesopotamia and North America (Li et al. 2020b). To achieve higher accuracy in land-cover changes detection, we compared data from the FLDAS against the GLDAS model data and the accuracy assessment is presented and discussed in subsequent sections. The objective is further strengthened by conducting a time series analysis of some hydrological variables namely precipitation, evapotranspiration, and soil moisture over selected areas within the region of interest where major class changes were observed.

\section{Data and Methods}

\subsection{Study Region}

The terrain surrounded by the Mediterranean Sea and seven member states from Europe, Africa, and Asia is known as Mediterranean region (Fig. 2). The Mediterranean region exists between approximately $30^{\circ}-40^{\circ} \mathrm{N}$ and $8^{\circ}-40^{\circ} \mathrm{E}$ covering parts of Europe and Africa continents (Anon 2021a). In general, the weather is characterized as warm and sunny throughout the year. The specific regional features such as hot summer with high ET and cool, humid winter have high impact on the biodiversity of this region (European Commission 2021). The average precipitation is about 20 in. of annual rain fall (Anon 2021c). During the winter months, the average temperature varies between $35^{\circ}$ and $60^{\circ}$ and in warmest month average temperature is about 72 degrees (Anon 2021c). Vegetation in the Mediterranean region can survive long dry summers and typical vegetation types found in this region are forests, woodlands, savannas, shrublands, and grasslands (Anon 2021b). Short trees and evergreen shrubs are the common tree species as they can last the summer's heat. The Mediterranean region undergoes exceptional threats due to human invention. The wide variety in biodiversity in this region has also gained tourist attraction which leads to the destruction of coastlines (European Commission 2021). In addition to that, limited water resources, consistent threat from forest fires, and impact of climate change are a big challenge for Mediterranean agriculture and sustainable development. The reference to months in this study is given by DJF (Dec-Feb), MAM (Mar-May), JJA (Jun-Aug), and SON (Sep-Nov).

\subsection{Data}

The FLDAS dataset used in this study is designed to facilitate forecast requirements associated with food security assessment in data-sparse, developing country settings (McNally et al. 2017; NASA GSFC Hydrological Sciences Laboratory (HSL) 2018). It has been operational since 1982 and still running. The spatial resolution of FLDAS is $0.1^{\circ}$ and $0.25^{\circ}$ depending on the land surface model used, while the temporal resolution is daily output of 15 -min, time steps. The various information that can be gleaned from datasets are elevation, vegetation cover, albedo, greenness, soil structure, and others (McNally et al. 2017). For this study, we used parameters including evapotranspiration and soil moisture (0-10 $\mathrm{cm}$ underground) from FLDAS data.

The GLDAS dataset used in this study captures the ground-based observational data and combining advanced land surface modeling and data assimilation techniques, generates optimal fields of land surface states, and fluxes at a global scale (Kansara et al. 2021). It has been operational since 1948 and still running. The spatial resolution of GLDAS is $0.1^{\circ}$ and $0.25^{\circ}$ depending on the land surface model used, while the temporal resolution is 3 hourly output of 15-min time steps. The various information that can be gleaned from datasets is elevation, vegetation cover, soil structure, and others. For this study, we used parameters 
Fig. 2 The maps of land-cover types (a) and shuttle radar topography mission elevation (b) with country boundaries of the Mediterranean region
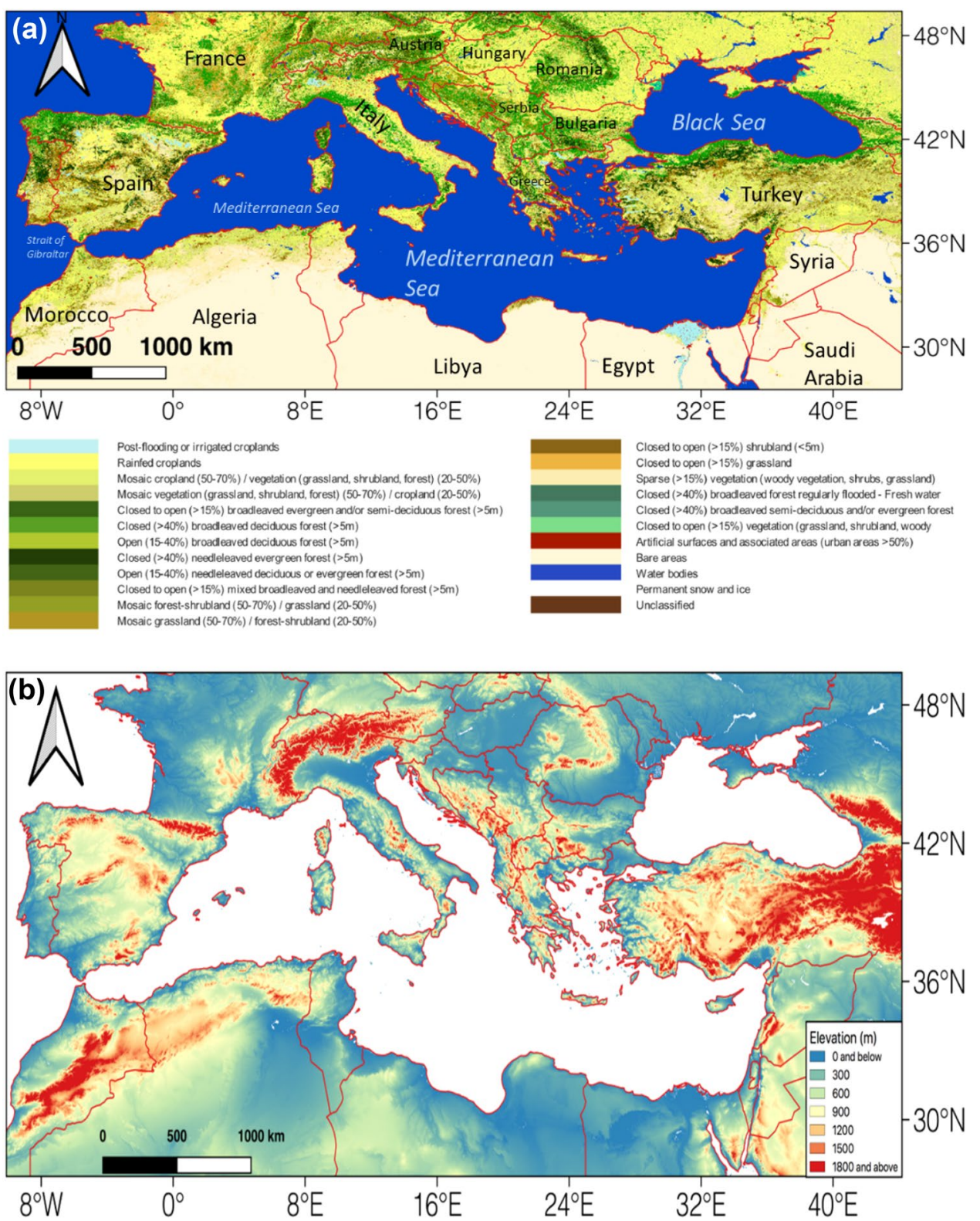

such as evapotranspiration and soil moisture from GLDAS data (Rodell et al. 2004).

NASA-USDA global soil moisture data (Bolten et al. 2010; Bolten and Crow 2012; Kerr and Levine 2008) used in this study provides soil moisture information such as surface and subsurface soil moisture $(\mathrm{mm})$, soil moisture profile (\%), and surface and subsurface soil moisture anomalies across the globe at $0.25^{\circ} \times 0.25^{\circ}$ spatial resolution. The dataset is available since 2010 . This dataset is generated by integrating satellite-derived Soil Moisture Ocean Salinity (SMOS) data into the model derived Ensemble Kalman Filter (EnKF) data. Thus, this model-based soil moisture prediction enhances the accuracy of predictions for areas such as Southern Africa and Middle East where they lack good quality precipitation data. For this study, we used surface soil moisture (SSM): mm parameter. CHIRPS Pentad (climate hazards group infra-red precipitation with station data) (version 2.0 final) (Funk et al. 2015) used in this study contains $0.05^{\circ}$ resolution satellite imagery of quasi-global precipitation data which is used for time-series analysis to show the precipitation trends and seasonal differences within the study area.

The moderate resolution imaging spectroradiometer (MODIS) data from both, the Terra and Aqua satellites, were employed in this analysis. To assess land-cover changes in this work, the MODIS VI products (MOD13), that provide spatial and temporal time series comparisons of global vegetation conditions, were utilized. Specifically, the MOD13A2.006 product (from Terra MOD13 series) was used that provides two vegetation indexes data, namely, the 
Normalized Difference Vegetation Index (NDVI) and the EVI, that has been operational from 2000 to present (Didan et al. 2015). The spatial resolution of this data product is $1 \mathrm{~km}(\mathrm{~km})$ while having a multi-day temporal resolution. Moreover, the MOD16A2.006 data product (from Terra MOD16 series) was also used for the ET analysis, that has been operational from 2001 to present (Running et al. 2017). The MOD16 series output is based on the logic of the Penman-Monteith equation and uses daily meteorological reanalysis data as well as 8-day remotely sensed vegetation property dynamics as inputs. This data product contains layers of composited ET, latent heat flux (LE), potential ET (PET), and potential LE (PLE) along with a quality control layer. The spatial resolution is $500 \mathrm{~m}(\mathrm{~m})$ while having multi-day temporal resolution. Here, we also used the third data product from MODIS, which is the Terra and Aqua combined MODIS land-cover type (MCD12Q1) Version 6, which has been operational from 2001 to 2019 (Friedl and Sulla-Menashe 2015). This data product provides global land-cover types and is derived using supervised classifications of MODIS Terra and Aqua reflectance data. It has a spatial resolution of $500 \mathrm{~m}$ while a yearly temporal resolution.

All the datasets have been retrieved using the Google Earth Engine platform (Gorelick et al. 2017) using its code editor.

\subsection{Methods}

The land-cover changes between 2009 and 2018 were processed by the ArcGIS change detection tool. Harmonic analysis is a method involving the representation of functions or signals as a superposition of elementary waves ( $\mathrm{Li}$ et al. 2020a). In this study, to estimate the variation of multiple hydrological factors (e.g., EVI, ET, and precipitation), we build the harmonic model $H(t)$ with elements of a constant band $\left(\beta_{0}\right)$, a linear term of slope $\left(\beta_{1}\right)$, and harmonic terms of amplitudes $\left(\beta_{2}, \beta_{3}, \beta_{4}\right.$, and $\left.\beta_{5}\right)$. The term $\beta_{1}$, associated with the linear part of the factor, represents the increasing/ decreasing trend, whereas a constant band $\beta_{0}$ represents the extent of consistency of the time series. Moreover, $f$ represents the fundamental frequency. The $\beta_{1}$ of the harmonic analysis can show linear trend of a series regardless of the seasonal variations. The $t$ is the time record for each parameter $H(t)$ (e.g., EVI and SSM). In this research, the value $\beta_{1}$ shows the yearly trend in the MENA region regardless of seasonal variations. Positive value represents increasing trend, and negative value decreasing:

$$
\begin{aligned}
H(t)= & \beta_{0}+\beta_{1} t+\beta_{2} \cos (2 \pi f t)+\beta_{3} \sin (2 \pi f t) \\
& +\beta_{4} \cos (4 \pi f t)+\beta_{5} \sin (4 \pi f t) .
\end{aligned}
$$

In addition, correlation analysis is also used to evaluate the relationship between two variables. In this study, lag correlation analysis was performed for all the bivariate combinations of evapotranspiration, soil moisture, precipitation, and EVI. These parameters are used to generate the changing trend map of the MENA region during 2009-2018, as well as lag correlation analysis using their anomalies value $X_{a}$ calculated in Eq. (2):

$X_{a}=X-\bar{X}$

with $X$ as the monthly value and $\bar{X}$ as the monthly mean value.

\section{Results}

\subsection{The Mean Distribution for Each Parameter}

Figure 3 illustrates the seasonal $(\mathrm{DJF}=\mathrm{Dec}-\mathrm{Feb}$, MAM = Mar-May, JJA = Jun-Aug, SON = Sep-Nov) maps of ET (Fig. 3a-3c), soil moisture (Fig. 3d-3f), EVI (Fig. 3g), and precipitation (Fig. 3h), as well as FLDAS and GLDAS datasets from 2009 to 2018 in the Mediterranean region.

For Terra ET (Fig. 3a), the overall lowest and highest recorded ET is illustrated during DJF and JJA, respectively. Both FLDAS (Fig. 3b) and GLDAS (Fig. 3c) ET products achieve a general consistency with Terra data. However, both datasets missed the seasonal higher ET in Egypt's Nile Delta region (Area A). Meanwhile, compared with satellite observations, the models show higher ET levels in Euphrates-Tigris region (Area B). A possible reasoning for this is provided in the discussion section of this manuscript.

For SSM (Fig. 3d), the overall lowest and highest recorded SM is illustrated during JJA and DJF, respectively. This contrasts with SM FLDAS (Fig. 3e) and SM GLDAS (Fig. 3f), where, though the highest recorded SM is during DJF, there is no obvious lowest recorded SM. The SSM is systematically lower that FLDAS/GLDAS, because it is surface SM, while FLDAS/GLDAS are entirely SM in $0-10 \mathrm{~cm}$. It is noted that FLDAS achieved better consistency with SSM than GLDAS. For example, the SSM patterns in Areas C, D, \& E can be found in FLDAS but not in GLDAS. GLDAS also has noises/inconsistencies within, such as patches in Fig. 3f.

For Terra EVI (Fig. 3g), the highest recorded EVI is during MAM in the north and during DJF in the Nile Delta, while the lowest recorded EVI is during DJF in the north and during SON in the southern area. Precipitation (Fig. 3h) is observed to vary among the regions. The highest recorded precipitation is during DJF in most regions (eastern Mediterranean), and during SON, high values have been recorded in 


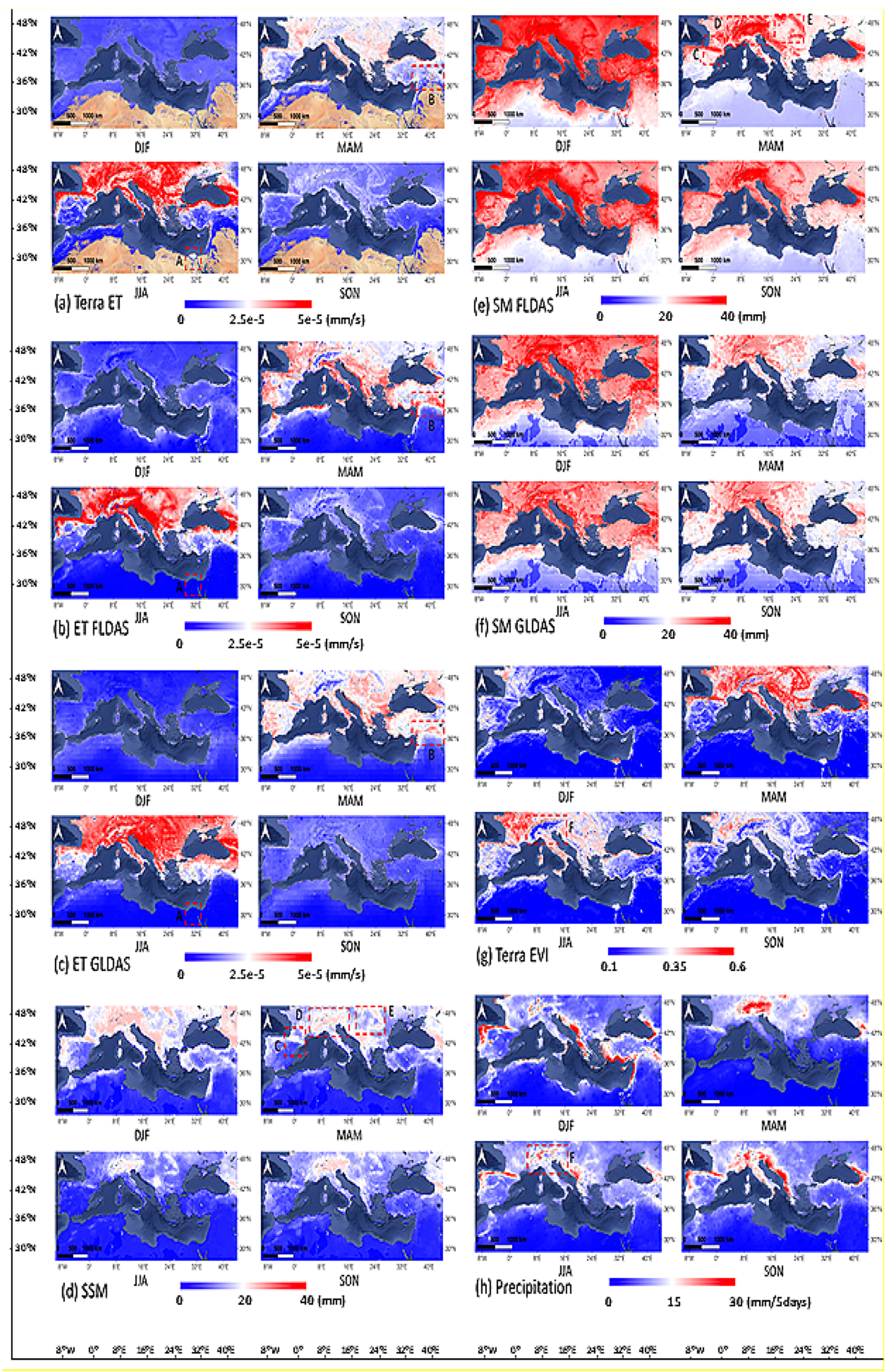

Fig. 3 Map of seasonal averages for ET, SM, EVI, and precipitation in Mediterranean region 
regions other than the eastern regions. The Area F (Fig. 3g, $3 \mathrm{~h}$ ) is a mountainous area (probably the Alps), which shows highest recorded precipitation during MAM. It has higher precipitation (Fig. 3h) and lower EVI (less vegetation) (Fig. 3g) than the surrounding areas.

\subsection{The correlation for each parameter}

Figure 4 demonstrates correlation plots for the bivariate combinations of parameters including ET, soil moisture, and precipitation. For each combination, dark blue and dark red colors represent the highly correlated areas and the correlation values in the figure range from -0.7 to 0.7 . Precipitation is very highly correlated with soil moisture and ET obtained from FLDAS data source (Fig. 4a, b) and moderately correlated in GLDAS data source (Fig. 4c, d). Precipitation vs ET FLDAS (Fig. 4a) shows strong positive correlation in North Africa, while Precipitation vs ET GLDAS (Fig. 4c) shows negative correlation in the Egypt/Nile Delta. Similar negative correlations are also observed north of the Mediterranean Sea in countries like Switzerland, Austria, some parts of Romania, Germany, and France. We suggest that these negative correlations are because of the high altitudes in these regions as they are basically, mountainous regions. The correlation values indicate that both FLDAS and GLDAS can have similar good results as observed in ET. According to Fig. $4 \mathrm{~b}$ and Fig. $4 \mathrm{f}$, there is a very strong positive correlation between precipitation with SM FLDAS and SSM, except for some weaker correlation in the mountainous regions. Precipitation vs SM GLDAS (Fig. 4d) has lesser correlation with precipitation when comparing precipitation with SSM and SM FLDAS. This is even a negative correlation in the Egypt/Nile Delta. There are some missing values predominantly seen in the African countries for Fig. 4e, g, i. There is a consistent negative correlation observed in the northern Mediterranean region between precipitation and Terra ET (Fig. 4e). There is moderate correlation between Terra ET and ET FLDAS (Fig. 4g), and Terra ET and ET GLDAS (Fig. 4i) as observed in the northern Mediterranean region, while there are high correlations among SSM and SM FLDAS (Fig. 4h), SSM and SM GLDAS (Fig. 4j), ET FLDAS and ET GLDAS (Fig. 4k), and SM GLDAS and SM FLDAS (Fig. 4l). For Fig. 4h, j-l, negative correlations can be observed in the Nile Delta region, which is not observed anywhere else in these figures.

\subsection{Trend Analysis}

The trend analysis is performed for hydrological factors such as Precipitation, EVI, Evapotranspiration, and SSM over the period of 2009-2018, as shown in Fig. 5. It is observed (Fig. 5a) that there is higher precipitation increase in the countries located to the east of the Mediterranean region (e.g., Iraq) while decrease to the west (e.g., Spain). There is a similar distribution for soil moisture in FLDAS (Fig. 5b), where the soil moisture values increase as moving from west to east. This high correlation between precipitation and SM FLDAS is also observed in the correlation figure (Fig. 4b). Soil moisture in GLDAS (Fig. 5c) has mixed trends over the entire region. Observational data SSM (Fig. 5d) has increasing trends throughout the region especially in the west, north, and east of the region. The southern region does not highlight any increasing or decreasing trend predominantly. However, as we observed earlier, SM FLDAS data seem to be a good fit due to the smoothness of data when compared with SM GLDAS and SSM. ET for observational data (Fig. 5e) has high values in the countries located to the north of this region (e.g., Italy, Greece, and France) with some missing values in the south. For ET FLDAS (Fig. 5f), it has lower recorded values when compared with ET. Most of the northern areas in ET FLDAS has low trend except for countries in Europe such as Bosnia, Romania, Slovenia, and countries in Africa such as Egypt and Libya. ET GLDAS (Fig. 5g) has mixed patterns like SM GLDAS (Fig. 5c), with higher values in the north-western part. Random patterns in GLDAS data for both soil moisture and ET probably suggest that there is noise in data, and it could be problematic to use this data for further analysis. For EVI (Fig. 5h), it appears to be decreasing from north to south, with countries in the north such as Germany, Romania, and Czechia having higher values, while countries in the south such as Libya, Egypt, and Iraq having lower trends.

\subsection{Land-Cover Change Detection}

Investigating the results obtained in 3.1-3.3 for climatology, correlation, and trend analysis, it can be observed that the landscape of this region has undergone a drastic change, over the decades. In this study, land-cover change detection was performed for Mediterranean region during the 2009-2018 period using MCD12Q1.006 MODIS Land Cover Type Yearly Global $500 \mathrm{~m}$ data. Land cover in Mediterranean region was classified into ten classes (Table 1).

Table 1 also displays the change (in \%) of different landcover types between each year from 2009 to 2018. Each column (Class 1-Class 10) represents the change for that class into other classes (corresponding rows). Almost all classes have changed into other classes except for class 6 (Urban and built-up lands) and class 10 (water bodies) where there are no changes. A primary reason for no or negligible changes in class 6 and class 10 could be because more and more lands are converted into urban lands because of a better standard of living, but urban lands are not changed into other types. Similarly, even water bodies are generally not changed into any other type. Approximately 10\% of Class 1 (Open Shrublands) in 2009 changed to other classes by 2018 and whereas 


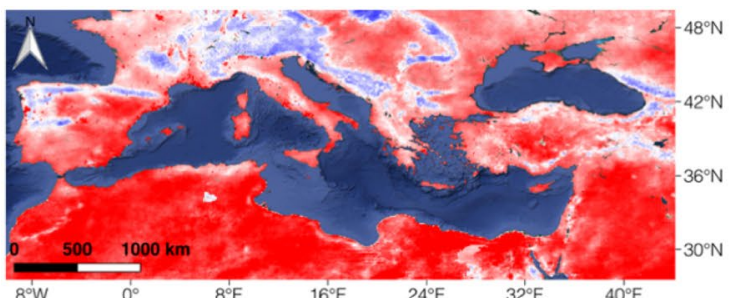

(a) Precipitation vs ET FLDAS

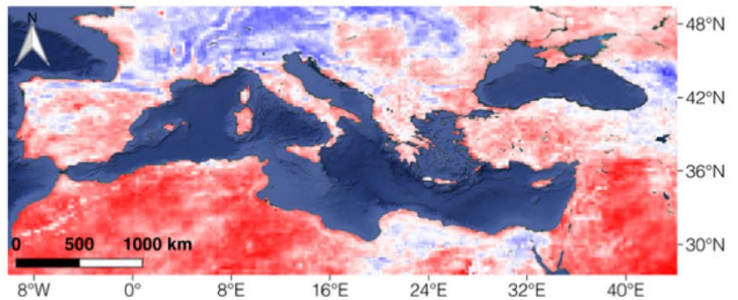

(c) Precipitation vs ET GLDAS

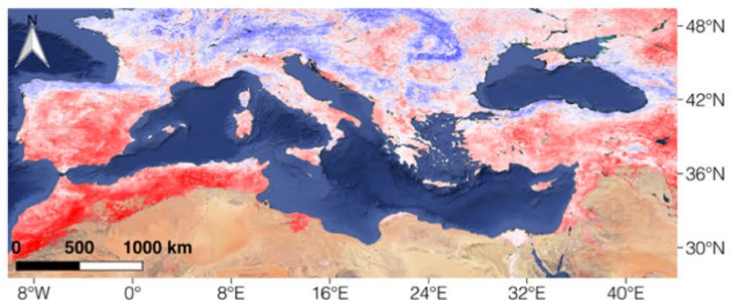

(e) Precipitation vs Terra ET

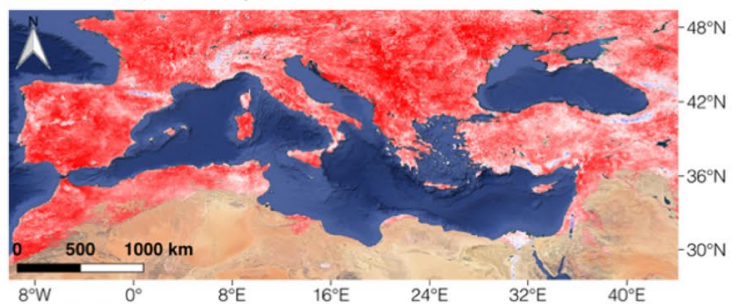

(g) Terra ET vs ET FLDAS

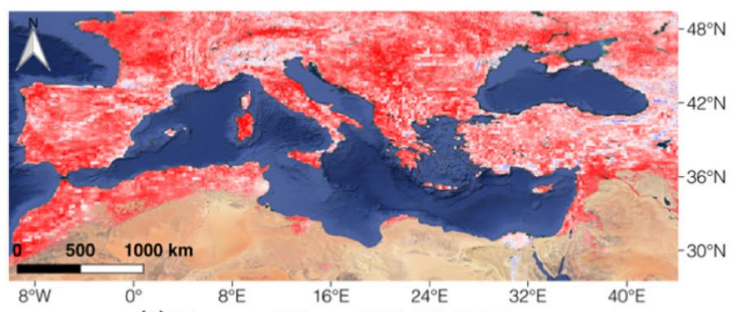

(i) Terra ET vs ET GLDAS

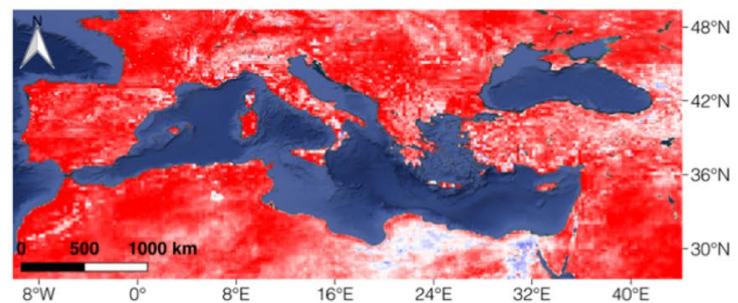

(k) ET FLDAS vs ET GLDAS

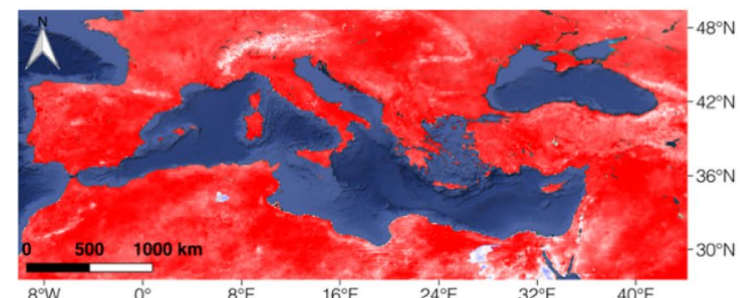

(b) Precipitation vs SM FLDAS

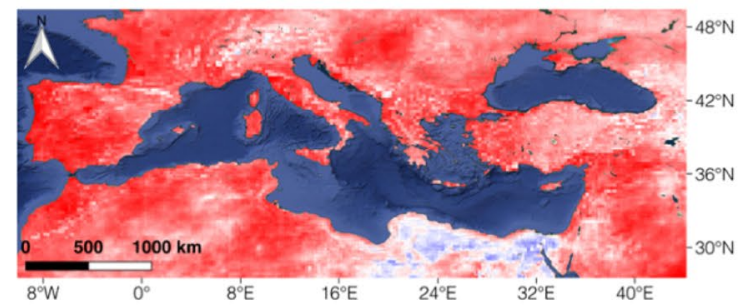

(d) Precipitation vs SM GLDAS

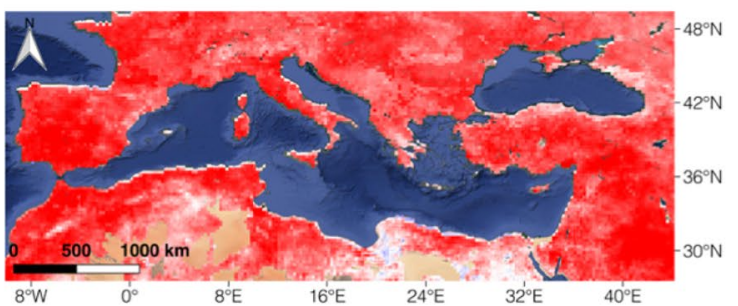

(f) Precipitation vs SSM

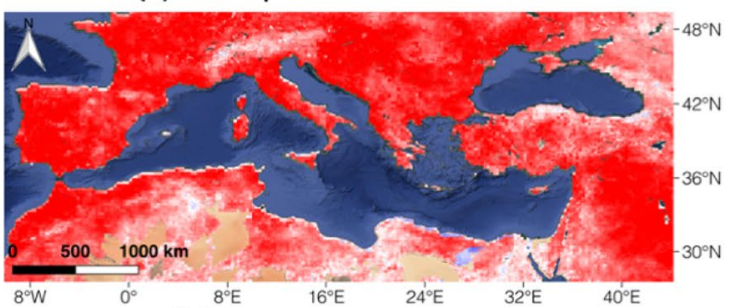

(h) SSM vs SM FLDAS

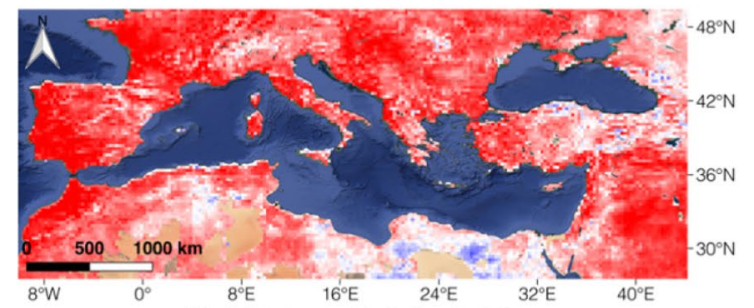

(j) SSM vs SM GLDAS

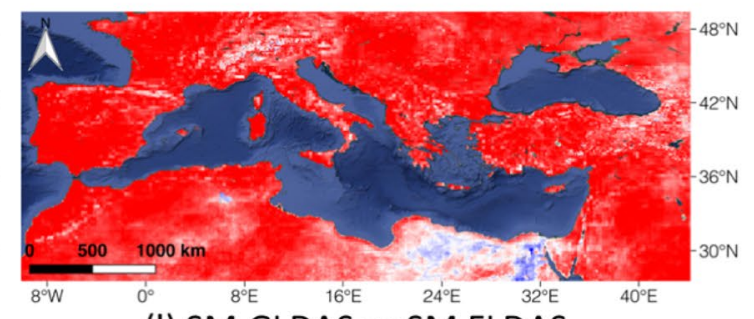

(I) SM GLDAS vs SM FLDAS

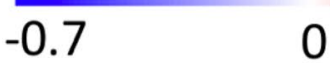

0.7 
4Fig. 4 Intercomparison among the modeled and observation datasets for the variable ET, soil moisture, and precipitation in Mediterranean region, and the brown region is the RGB background from Google Map

majority of these Open Shrublands ( 6\%) changed to Grasslands. About $9 \%$ of class 2 (Grasslands) in 2009 changed into other classes by 2018, and majority of these Grasslands ( $\sim 6 \%$ ) changed to Open Shrublands and Croplands. For class 3 (Evergreen Needleleaf Forests), there is an overall 15\% change and majority of these Evergreen Needleleaf Forests (about 10\%) changed into Grasslands. Approximately 11\% of Class 4 (Permanent Wetlands) in 2009 changed to other classes by 2018 , and majority of these Permanent Wetlands ( $\sim 8 \%$ ) changed to Grasslands. Class 5 (Croplands) changed to other classes by $5 \%$ where, major change is into the Grasslands. Class 7 (Cropland/Natural Vegetation Mosaics) had the highest percentage change $(\sim 20 \%)$ and the majority of these changes are into the Croplands (12\%) and Grasslands (7\%). Class 8 (Permanent Snow and Ice lands) changed by $15 \%$ over the period of 2009-2018 and, majority of these Permanent Snow and Ice lands changed into Barren lands (13\%). For Class 9 (Barren) and Class 10 (Water Bodies), the change into other land-cover types is significantly low $(\sim 1 \%)$.

Figure 6 provides a clear visualization of land-cover change over the period of 2009-2018. The color scheme in the legend represents the change from class $i$ to class $j$ where $i, j=1,2 \ldots 10$ and $i \neq j$. The zoomed areas of Fig. 6 demonstrate noticeable color changes, which emphasize that there is change of land-cover types in Mediterranean region over the period of 2009-2018. According to Fig. 6f, it could be observed that majority of land-cover changes in Iraq are from class 9 (Barren) to class 1 (Open Shrublands), and with some minor changes from Class 5 (Croplands) to Class 1 (Open Shrublands), Class 2 (Grasslands) to Class 5 (Croplands), and Class 1 (Open Shrublands) to Class 5 (Croplands). Figure 6e illustrates that there are changes from Class 1 (Open Shrublands) to Class 2 (Grasslands), Class 9 (Barren) to Class 2 (Grasslands), and Class 2 (Grasslands) to Class 5 (Croplands) in the Northern part of Egypt. For most part of Morocco and Libya, there are land-cover type changes such as Class 5 (Croplands) to Class 1 (Open Shrublands), Class 2 (Grasslands) to Class 1 (Open Shrublands), and Class 2 (Grasslands) to Class9 (Barren). Figure 6b, c demonstrates that in Turkey the noticeable change is from class 1 (Open Shrublands) to Class 2 (Grasslands) and in Greece its Class 5 (Croplands) to Class 2 (Grasslands). According to Fig. 6a most of the land-cover change for Spain is from Class 2 (Grasslands) to Class 1 (Open Shrublands) with few changes from Class 5 (Croplands) to Class 1 (Open Shrublands).

\subsection{The Time-Series of the Parameters for Selected Countries}

Figure 7 illustrates the time-series plots of soil moisture obtained from observational data (SSM), EVI, Precipitation, ET obtained from observational data (ET) within selected countries (Turkey, Spain, Italy, Greece, Tunisia, and Egypt) of Mediterranean region from 2010 to 2018. In general, there are random variations for all the selected countries within this period. From the observational data (SSM) (Fig. 7a), it is observed that there are lesser variations for most of the countries, except for the alternating SSM drop and rise observed in April for the years 2012, 2014, 2016, and 2018 for Spain. For Egypt, it can be observed that soil moisture level fluctuates closer to zero with very few deviations over the period. Such disagreements are also found for EVI (Fig. 7b) and Precipitation (Fig. 7c) for Egypt from 2010 to 2018. For EVI, in Turkey, there are significant low values observed in April 2012 and 2017, while significant high values observed in April 2018 compared to other countries.

All other selected countries have fewer variations, randomly scattered and no apparent seasonal patterns to be observed from the data. Greece appears to have dominant variations for precipitation (Fig. 7c) over the period compared to other selected countries with minimum observed in October 2012 and the maximum observed in November 2012. For ET observed from MODIS (Fig. 7d), it has significant variation for Greece where the lowest is recorded in June 2012 and the highest is recorded in June 2018. All the other countries seem to have similar variations over the period. There are apparent differences for almost all the parameters in all the selected countries as they are randomly scattered over the period.

\subsection{The Monthly Average of Soil Moisture, Precipitation, and EVI for Selected Countries}

Figure 8 illustrates monthly average of EVI, precipitation, and soil moisture for five major land types in selected countries (Turkey, Spain, Italy, Greece, Tunisia, and Egypt). In general, for Turkey, all types such as EVI, Precipitation, and Soil moisture are consistently variate (Fig. 8a-c). All the plotted land-cover types for EVI have maximum value in May and lowest in DJF. For precipitation, the lowest is observed during July-September, and in other months of the year, there are higher values with variations. Similar results can be observed for surface soil moisture such as lower during July-September than other months. This would be due to the high correlation between Precipitation and Soil moisture. Monthly average of EVI in Egypt (Fig. 8d) is plotted for land-cover types such as Artificial surfaces, Bare areas, Irrigated croplands, Mosaic vegetation, and water bodies. Irrigated croplands display strong seasonal pattern of low 


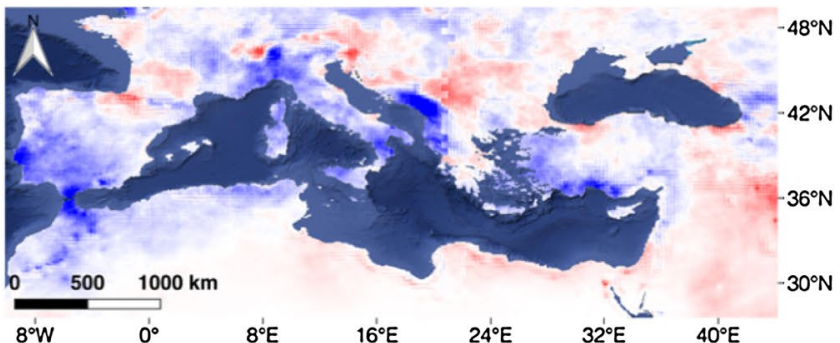

(a) Precipitation
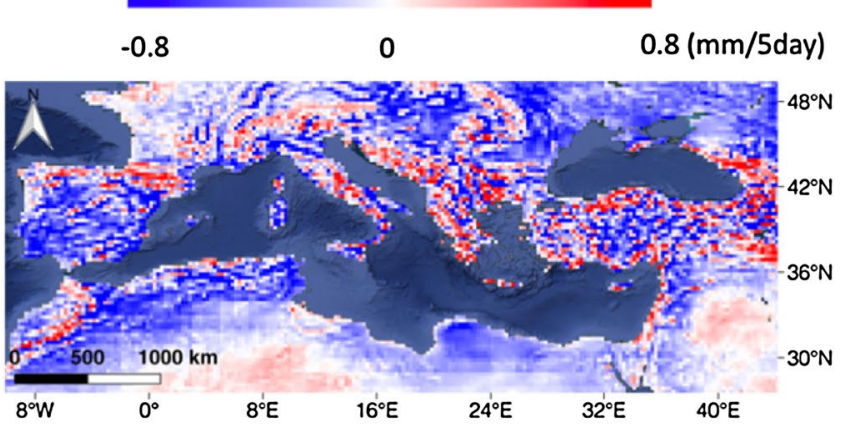

(c) SM GLDAS
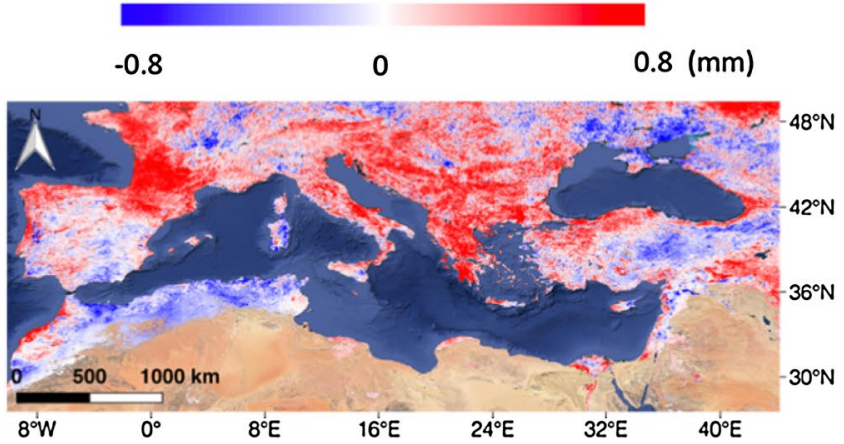

(e) ET

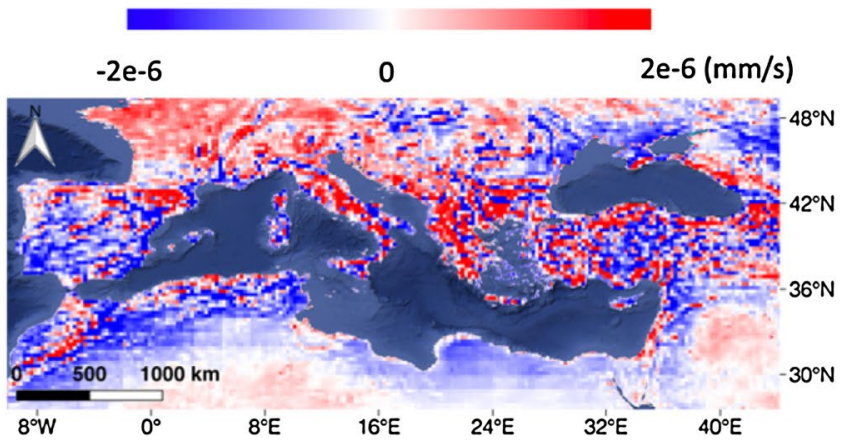

(g) ET GLDAS

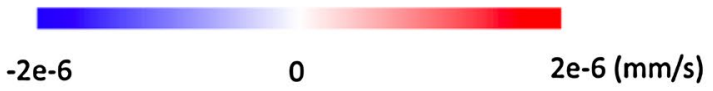

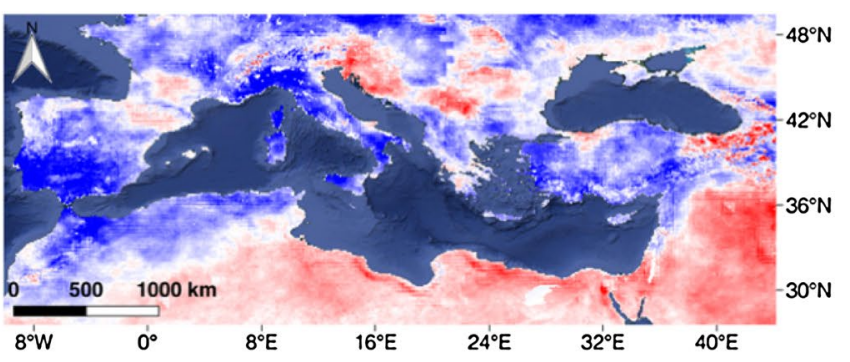

(b) SM FLDAS

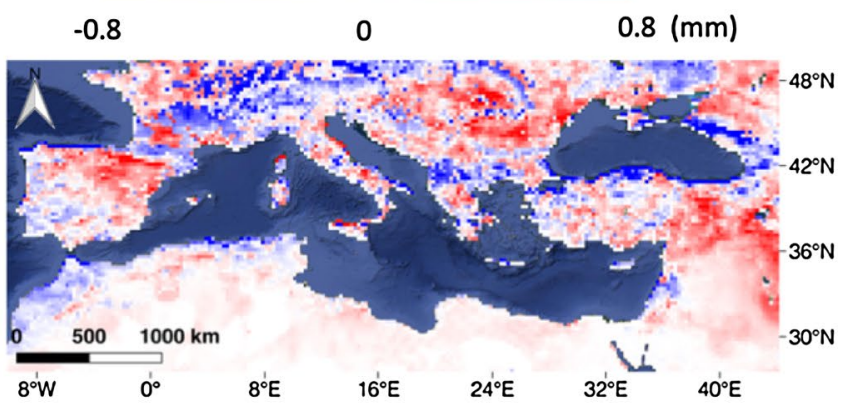

(d) SSM
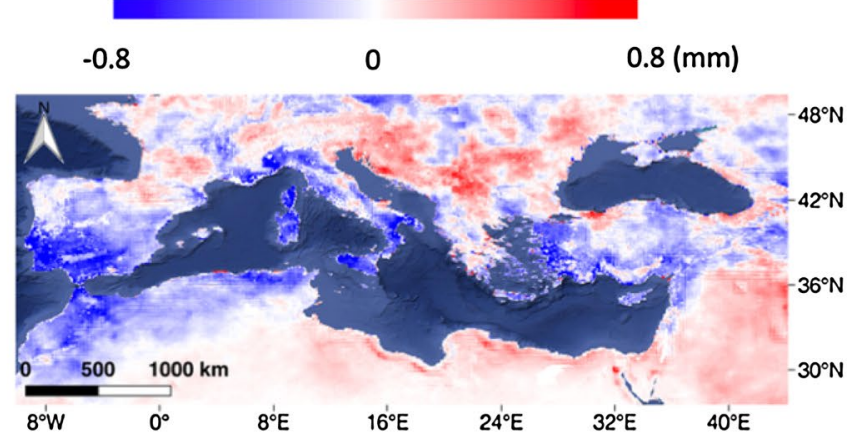

(f) ET FLDAS

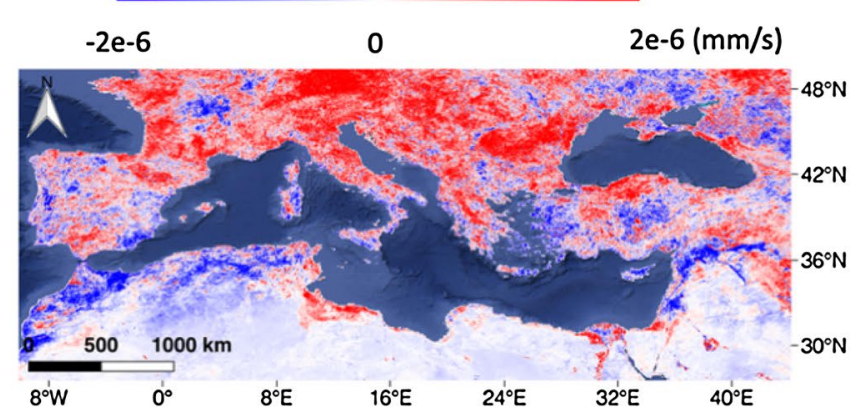

(h) EVI

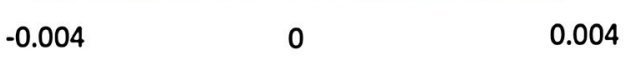

Fig. 5 The trend map of Precipitation, SSM, ET, and EVI obtained from observational data in Mediterranean region, and the brown region is the RGB background from Google Map

values in May and Sep/Oct but high values in summer and winter, while Mosaic vegetation shows weak seasonality. Other types including artificial surfaces, water bodies, and bare areas do not vary because of their low vegetation coverage. Monthly precipitation in Egypt (Fig. 8e) demonstrates the pattern of nearly no rainfall during summer, and higher 


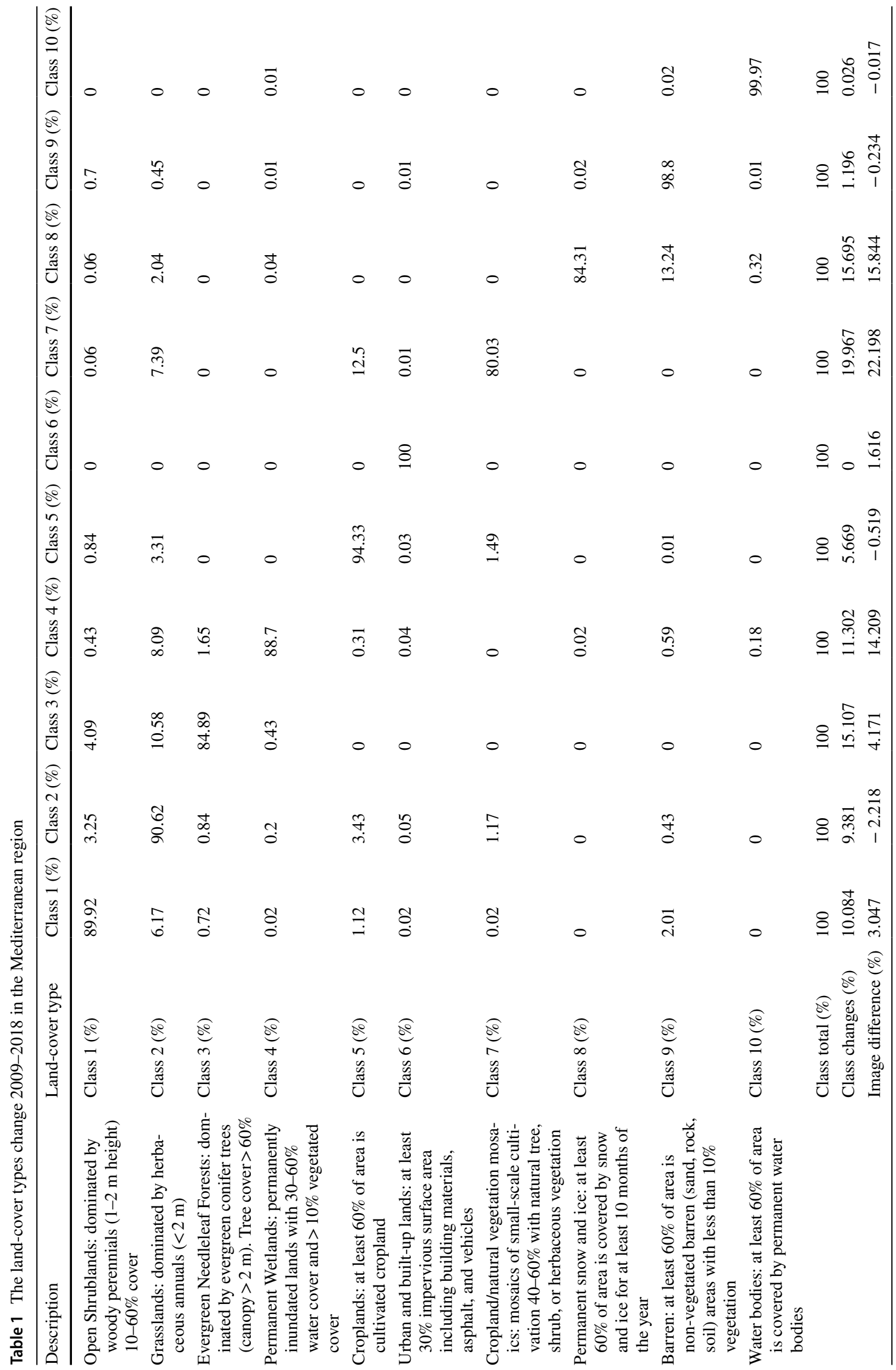




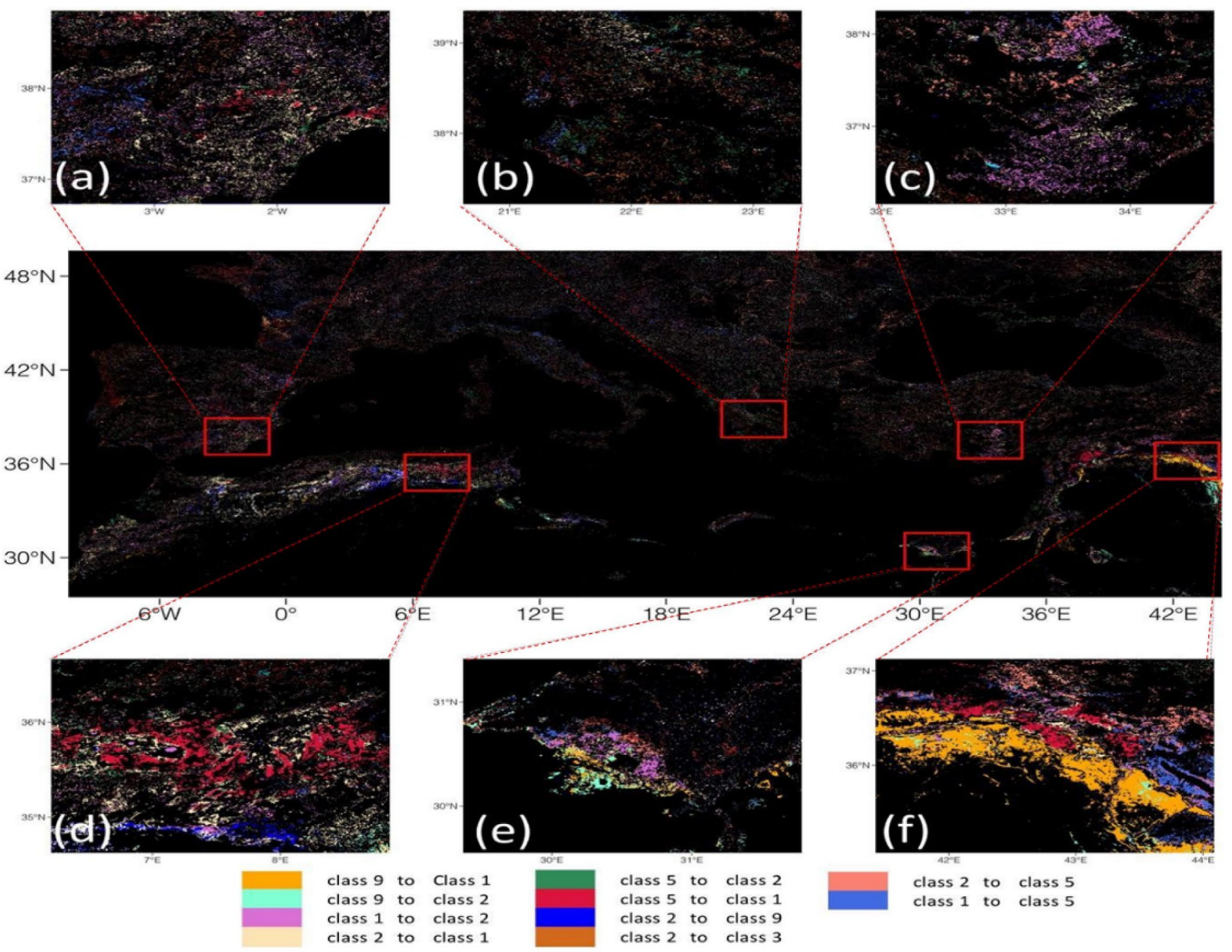

Fig. 6 Land-cover change detection, and class types can be referenced from Table 1. a South-eastern region of Spain; b Southern Greece; c) Southern Turkey; d Northern region of Algeria; e Northern Egypt; f Northern Iraq

values during winter yet still low $(<25 \mathrm{~mm})$ and the lowest compared to other selected countries. Vegetation types such as Irrigated croplands and Mosaic vegetation for surface soil moisture in Egypt (Fig. 8f) has the highest values during winter but low during fall and summer. Water bodies seems to be consistently low throughout the year and the Artificial surfaces have a peak and highest values compared to other land types during July which may be due to human watering vegetation.

In particular, EVI for Tunisia (Fig. 8g) has higher values during Spring for all land-cover types, while the highest is observed for Rainfed croplands. Precipitation (Fig. 8h) and soil moisture (Fig. 8i) for Tunisia are lowest in July and higher in DJF period. All the land-cover types in Tunisia have very identical trends for both Precipitation and Soil moisture. Spain has the maximum EVI (Fig. 8j) observed during the April-May and minimum precipitation (Fig. 8k) observed during July-August for all the land-cover types.
Parallel to Precipitation, soil moisture (Fig. 81) also has lower values during July-September. Apparent coherency is observed for Precipitation and soil moisture trends for all land-cover types in Spain. In Italy, the largest monthly EVI (Fig. 8m) is found for Broadleaved Deciduous Forest, which is higher than others during May-October and highest in May-June. Monthly precipitation in Italy (Fig. 8n) is low in July-August and highest in November. Like precipitation, soil moisture in Italy (Fig. 8o) is high in winter and spring and low during July-August. Analogous to Precipitation and soil moisture in Spain, it can be examined that Italy also has high correlation between all land-cover types for these two variables. EVI in Greece (Fig. 8p) is high in May-June as observed in Italy. For the precipitation in Greece (Fig. 8q), there is a small peak in May and highest during Fall-Spring. Low precipitation is observed during July-August for all types in Greece. Soil moisture (Fig. 8r) is low in July-September and high during winter and spring in Greece. 

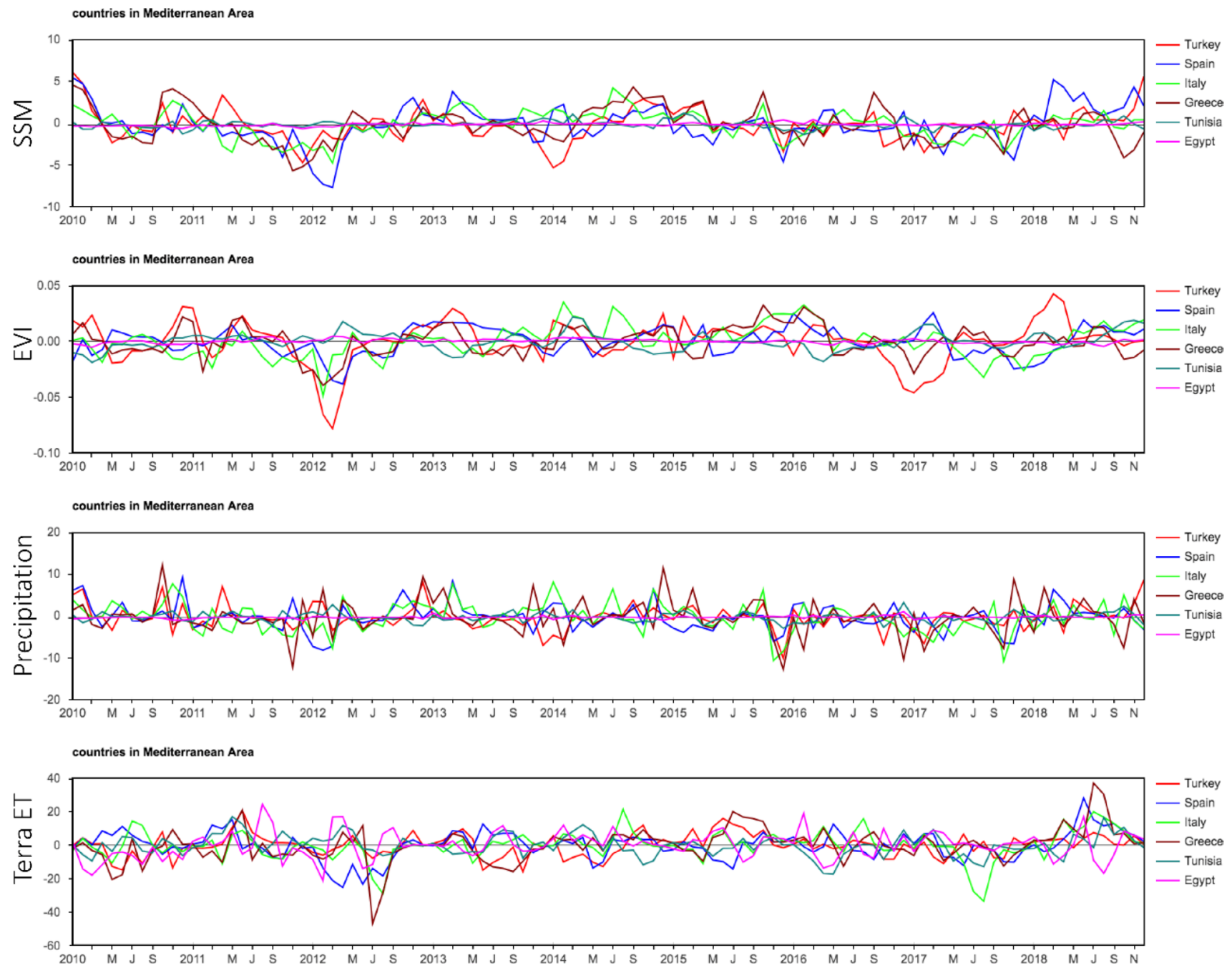

Fig. 7 Time-series of SSM (in mm), EVI, Precipitation (in mm), and Terra ET (in $10^{-5} \mathrm{~mm} / \mathrm{s}$ ) over six locations within the Mediterranean region from 2010 to 2018

\section{Discussion}

From the climatology plots (Fig. 3), we observed that even though data were collected from different sources such as FLDAS and GLDAS, there is apparent coherency for the same variables such as ET and SM. However, when comparing model results with observational data, it could be noticed that seasonal averages from Terra satellite for ET were lower as compared to the seasonal averages retrieved from FLDAS and GLDAS. The data from each source, namely, Terra satellite, FLDAS, and GLDAS, were aggregated over the decade 2009-2018. A possible explanation for the difference in values could be the difference in temporal resolution of these data sources. The Terra satellite records real-time observations only once in 16 days as compared to the FLDAS and GLDAS data which record observations throughout the day in 15 min time intervals. ET values in the region of interest would keep on changing as the day progresses, which would explain the difference between the seasonal averages of Terra satellite retrievals and the models (FLDAS/GLDAS). As access to ground observations in the region of interest was lacking, the results could not be validated to check whether the Terra satellite data were underestimating, or the models were overestimating the ET values. Observational data such as SSM from Fig. 3f also have some noise and do not provide a smooth distribution. Similar results can be observed from Figs. 4 and 5 for FLDAS, GLDAS, and SSM data plotted for correlation and trend. The study found that climatology of soil moisture and ET obtained from FLDAS seems to have less noise compared to the same parameters obtained from GLDAS. It can be found that there are high values recorded for both soil moisture and ET in the countries located to the North such as France, Germany, Austria, and Italy. Low values for soil 


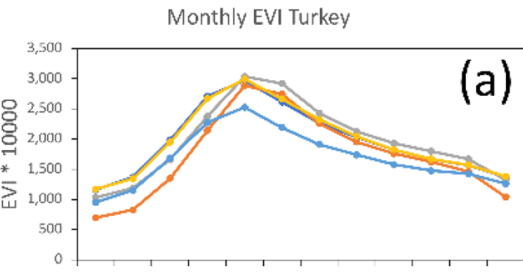

Jan Feb Mar Apr May Jun Jul Aug Sep Oct Nov Dec $\rightarrow$ Mosaic Cropland $\rightarrow$ - Mosaic Vegetation $\rightarrow$-Open Shrubland $\rightarrow$ Rainfed Croplands $\rightarrow$-Sparse Vegetation

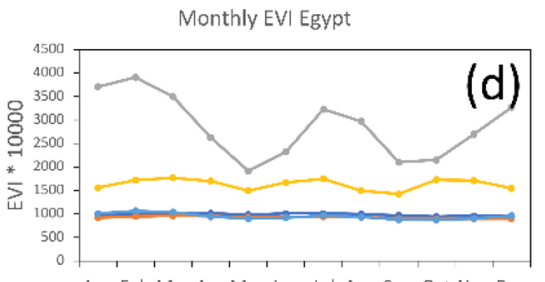

Jan Feb Mar Apr May Jun Jul Aug Sep Oct Nov Dec $\rightarrow$ Artificial Surfaces $\rightarrow$ Bare areas

$\rightarrow$ Mosaic Vegetation $\rightarrow$ Water Bodies
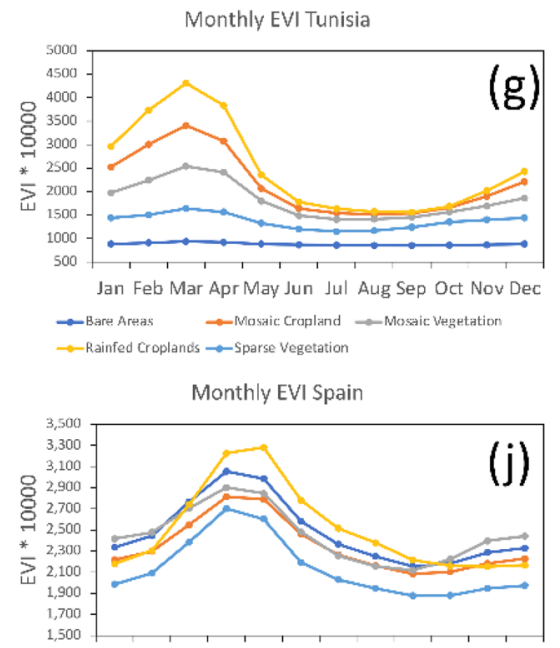

Jan Feb Mar Apr May Jun Jul Aug Sep Oct Nov Dec

$\rightarrow$ Mosaic Cropland $\rightarrow$ Mossic Vegetation - Open Shrubland

$\rightarrow$ Rainfed Croplands $\rightarrow$-Sparse Vegetation

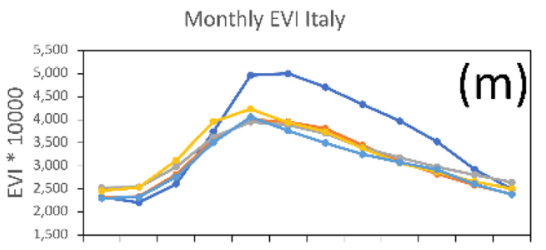

Jan Feb Mar Apr May Jun Jul Aug Sep Oct Nov Dec $\rightarrow$ Broadle aved Deciduous Forest $\rightarrow-$ Mosaic Cropland

$\rightarrow$ Mosair. Vegetation $\quad$-Rainfed Croplands

$\rightarrow$ Sparse Vegetation

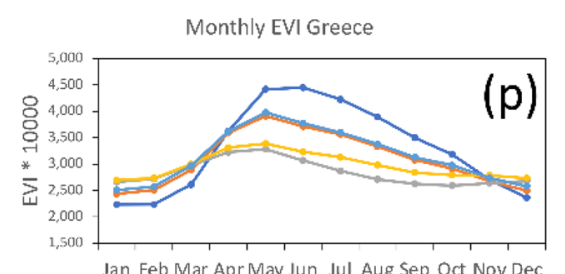

Jan Feb Mar Apr May Jun Jul Aug Sep Oct Nov Dec $\rightarrow$ Brosdle sved Deciduous Forest $\rightarrow$-Mo saic Cropland $\rightarrow$ Mosair Vegetation $\rightarrow$ Open Shrubland $\rightarrow$ Rainfed Croplands

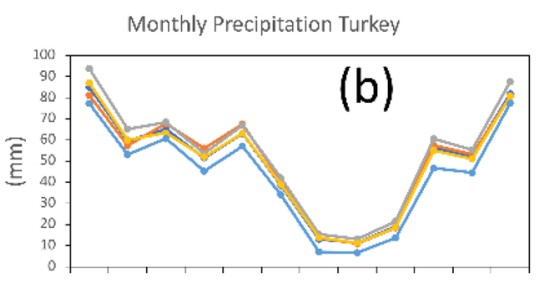

Jan Feb Mar Apr May Jun Jul Aug Sep Oct Nov Dec $\rightarrow$ Mosaic Cropland $\rightarrow$ - Masaic Vegetation $\rightarrow$-Open Shrubland $\rightarrow$ Rainfed Croplands $\rightarrow-$ Sparse Vegetation

Monthly Precipitation Egypt

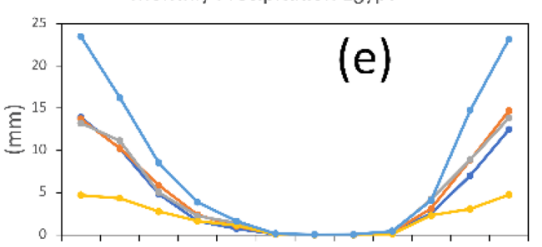

Jan Feb Mar Apr May Jun Jul Aug Sep Oct Nov Dec $\rightarrow$-Artificial Surfaces $\rightarrow$ Bare areas $\rightarrow$-irrigated Croplands $\rightarrow$ Mosaic Vegetation $\rightarrow$-Water Bodies

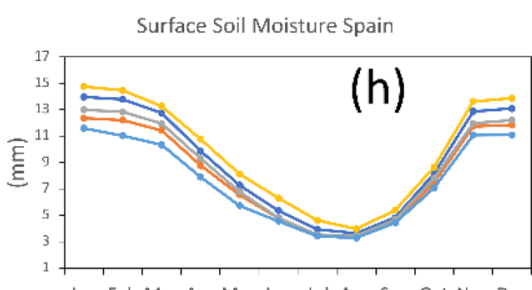

Jan Feb Mar Apr May Jun Jul Aug Sep Oct Nov Dec $\rightarrow$ Mosaic Cropland $\rightarrow$-Mosaic Vezetation $\rightarrow$ Open Shrubland $\rightarrow$ Rainfed Croplands $\rightarrow$ sparse Vegetation

Monthly Precipitation Spain

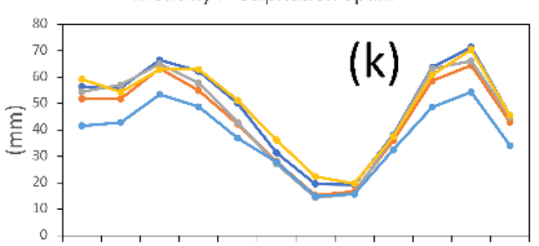

Jan Feb Mar Apr May Jun Jul Aug Sep Oct Nov Dec $\rightarrow$ Mosaic Cropland $\rightarrow$-Mosaic Vegetation $\rightarrow$-Open Shrubland $\rightarrow$ Rainfed Croplands $\rightarrow$-Sparse Vegetation

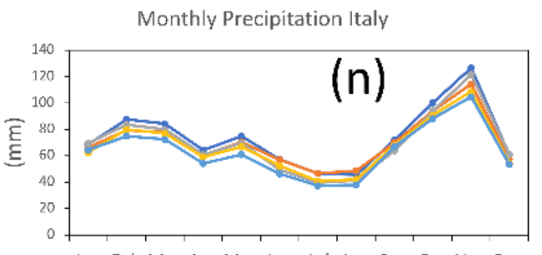

Jan Feb Mar Apr May Jun Jul Aug Sep Oct Nov Dec $\rightarrow$ Broadleaved Deciduous Forest $\rightarrow$ Massic Cropland

$\rightarrow$ Mosaic Vegetation $\rightarrow$-Rainfed Croplands $\rightarrow-$ Sparse vecetation

Monthly Precipitation Greece

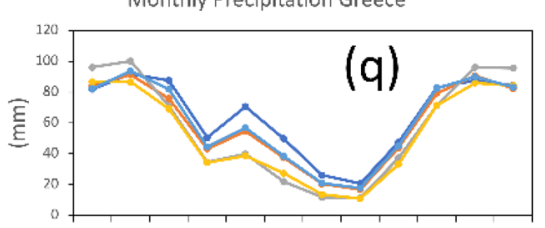

Jan Feb Mar Apr May Jun Jul Aug Sep Oct Nov Dec $\rightarrow$-Broadleaved Deciduous Forest - $\rightarrow$ Mosaic Cropland $\rightarrow$ Musaic Vegetation $\rightarrow$ Open Shrubland $\rightarrow$ Rainfed Croplands

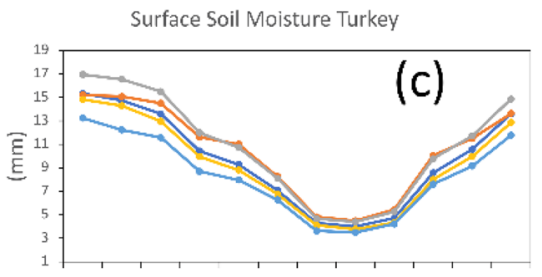

Jan Feb Mar Apr May Jun Jul Aug Sep Oct Nov Dec $\rightarrow$-Massic Crupland $\rightarrow$-Mosair Vegetation - a-Open Shrubland $\rightarrow$ Rainfed Croplands $\rightarrow$-Sparse Vegetation

Surface Soil Moisture Egypt

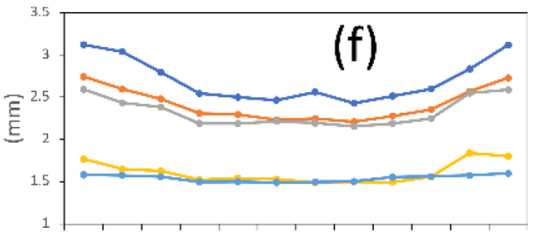

Jan Feb Mar Apr May Jun Jul Aug Sep Oct Nov Dec

$\rightarrow$ Artificial Surfaces an Bare areas armigated Croplan de

$\rightarrow$ Mosaic Vegetation $\rightarrow$ Water Bodies

Surface Soil Moisture Tunisia

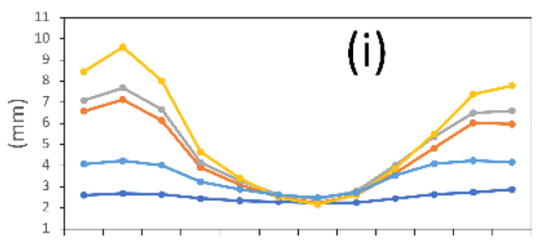

Jan Feb Mar Apr May Jun Jul Aug Sep Oct Nov Dec $\rightarrow$ Bare Areas $\rightarrow$ Mosaic Cropland $\rightarrow$ Mosaic Vegetation

$\rightarrow$ Rainfed Croplands $\rightarrow-$ Sparse Vegetation

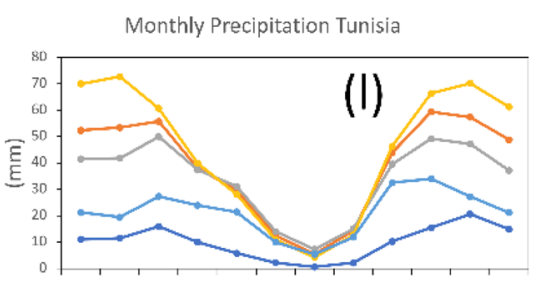

Jan Feb Mar Apr May Jun Jul Aug Sep Oct Nov Dec $\rightarrow$ Bare Areas $\rightarrow$ Mosaic Cropland $\rightarrow$ Mastic Vegetation $\rightarrow$ Rainfed Croplands $\rightarrow$ Sparse Vegetation

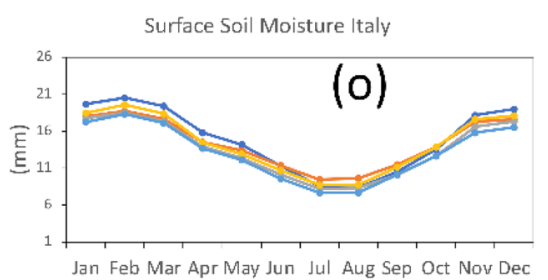

Jan Feb Mar Apr May Jun Jul Aug Sep Oct Nov Dec -Broadleaved Decidu ous Forest $\rightarrow$ Mosaic Cropland

$\rightarrow$ Mosaic Vegetation $\quad \rightarrow$ Rainfed Croplands $\rightarrow$-Sparse vezetation

Surface Soil Moisture Greece

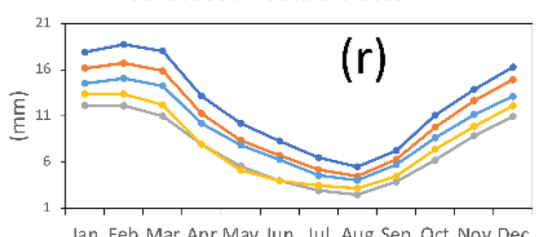

Jan Feb Mar Apr May Jun Jul Aug Sep Oct Nov Dec $\rightarrow$ Broadleaved Decidu ous Forest $\rightarrow$-Mosaic crop land

$\rightarrow$ Massic Vegetation $\rightarrow$ Open Shrubland

- Rainfed Croplands

Fig. 8 Monthly average of soil moisture, precipitation, and EVI for Turkey, Egypt, Tunisia, Spain, Italy, and Greece 
moisture and ET are recorded for countries such as Algeria, Libya, Egypt, and Northern Saudi Arabia. FLDAS data have better visualization and clear overview in those regions, suggesting that FLDAS performs better in these regions than GLDAS in terms of its coherency with the observed hydrological parameters.

There are some known issues with GLDAS-1 data, which might have caused noise in soil moisture and ET analysis performed with GLDAS model. The GLDAS-2.1 is revised with upgraded models forced by a combination of GDAS, disaggregated GPCP, and AGRMET radiation data sets. However, the results from this study emphasize that GLDAS-2.1 still has the same issues as GLDAS-1. On the other hand, FLDAS data are specifically generated for seasonal drought monitoring and trend analysis using rainfall data obtained specifically from Africa regions. The crop water balance model utilized by the FLDAS is operated using a few datasets such as FEWS NET (Verdin and Klaver 2002), NOAA Climate Prediction Centre, and the CHIRPS, a quasi-global rainfall dataset (Xie and Arkin 1997). Additionally, FLDAS data include temporal disaggregation mechanism where the rainfall data are used in crop water balance models and irrigation models. Since FLDAS data have specific features related to climatology and the study region with lesser drawbacks compared to GLDAS data, FLDAS data would be ideal for future study. Even though, GLDAS data are important for researches in Egypt, due to high correlations, similar patterns and trends, FLDAS data would be more precise.

In this study, the relationships between the hydrological variables and land-cover changes were analyzed. Some regions have drying trends, so that most of the Open shrub lands have changed to barren lands. On the other hand, some regions have land-cover changes by human activities, such as Egypt, which has reclaimed croplands. In northern Iran and Iraq, areas with at least $60 \%$ of non-vegetated barren areas have converted to the open shrublands. Most of the croplands in Algeria have changed to open shrublands possibly due to the drying tendency. The trend analysis of hydrological parameters resonates with the results obtained above, such that there is a decrease in EVI, ET, and soil moisture for regions such as Egypt, Iran, Iraq, and Algeria. Declining patterns of above hydrological variables is an indication of drying trends that cause land-cover changes.

In this study, the intercomparing between six Mediterranean countries in terms of their historical records and monthly climatology of EVI, SSM, ET, and precipitation are also presented in the Figs. 7 and 8. Mediterranean region is diverse among the different countries in the region. Countries to the south of this region such as Egypt, Libya, Iran, and Tunisia experience more dryer and desert climate than countries to the north such as Spain, Italy, France, and Germany. Thus, the selection of the proper hydrological products is important for some countries such as Egypt, which does not demonstrate noticeable fluctuations for EVI, ET, and SM throughout the year. Egypt tends to have consistent pattern throughout the year for the hydrological variables, which makes it difficult to detect land-cover changes. On the other hand, Mediterranean areas in Europe widely face land-cover changes due to human intervention activities such as land abandonment, which results in soil erosion and fire risks. Thus, to detect land-cover changes caused by natural phenomena and human induced changes, a significant attention needs to be provided to the countries by considering their geological location and diversity among different countries.

\section{Conclusion}

This study presents the association between land-cover changes and hydrological parameters such as EVI, ET, precipitation, and soil moisture in the Mediterranean region. Significant changes in land-cover types of Open shrublands, Grasslands, Evergreen forests, Wetlands, Croplands, Barren lands, and Water bodies are observed throughout the Mediterranean region. Significant changes in land-cover types are well described by the climatology, correlation, and trend analysis of hydrological parameters.

The above-mentioned analysis is performed using observational data and model data sources such as FLDAS and GLDAS. FLDAS data proved to have better performance with exploring trends and patterns with less noise and smoother data compared to GLDAS. Trend analysis of the hydrological variables such as EVI, ET, and soil moisture demonstrate the drying pattern over time, which cause Landover changes. Most of the grasslands, and croplands in Egypt, Iran, Iraq, and Algeria have converted to non-vegetated lands over time and it was well illustrated by trend maps of hydrological variables constructed in this study. To analyze the seasonal variations, time series of EVI, precipitation, and soil moisture are constructed using monthly averages for the selected countries such as Egypt, Turkey, Spain, Italy, Greece, and Tunisia.

Acknowledgements The authors acknowledge the support from the Earth Systems Science and Data Solutions (EssDs) Lab and Computational and Data Sciences Graduate Program, Schmid College of Science and Technology, Chapman University. The authors also acknowledge the team at Google Earth Engine through which all the satellite data were used in this study. 


\section{Declarations}

Conflict of Interest The author declares no known competing financial interests or personal relationships that could have appeared to influence the work reported in this paper.

Open Access This article is licensed under a Creative Commons Attribution 4.0 International License, which permits use, sharing, adaptation, distribution and reproduction in any medium or format, as long as you give appropriate credit to the original author(s) and the source, provide a link to the Creative Commons licence, and indicate if changes were made. The images or other third party material in this article are included in the article's Creative Commons licence, unless indicated otherwise in a credit line to the material. If material is not included in the article's Creative Commons licence and your intended use is not permitted by statutory regulation or exceeds the permitted use, you will need to obtain permission directly from the copyright holder. To view a copy of this licence, visit http://creativecommons.org/licenses/by/4.0/.

\section{References}

Anon (2021a) Mediterranean climate. Wikipedia [online]. https:// en.wikipedia.org/w/index.php?title=Mediterranean_climate $\&$ oldid=998354219. Accessed 22 Feb 2020

Anon (2021b) Mediterranean forests, woodlands, and scrub. Wikipedia [online]. https://en.wikipedia.org/w/index.php?title=Medit erranean_forests,_woodlands,_and_scrub\&oldid=998439516. Accessed 22 Feb 2020

Anon (2021c) Mediterranean-climate types for Kids [online]. https://sites.google.com/site/climatetypes/mediterranean. Accessed 18 Jan 2021

JE Bagley AR Desai KJ Harding PK Snyder JA Foley 2014 Drought and deforestation: has land cover change influenced recent precipitation extremes in the Amazon? J Clim 27345361 https:// doi.org/10.1175/JCLI-D-12-00369.1

RA Betts 2000 Offset of the potential carbon sink from boreal forestation by decreases in surface albedo Nature 408187190 https://doi.org/10.1038/35041545

JD Bolten WT Crow 2012 Improved prediction of quasi-global vegetation conditions using remotely sensed surface soil moisture: improved prediction of vegetation Geophys Res Lett https://doi. org/10.1029/2012GL053470

JD Bolten WT Crow X Zhan TJ Jackson CA Reynolds 2010 Evaluating the utility of remotely sensed soil moisture retrievals for operational agricultural drought monitoring IEEE J Sel Top Appl Earth Obs Remote Sens 35766 https://doi.org/10.1109/ JSTARS.2009.2037163

RE Dickinson 1983 Land surface processes and climate-Surface albedos and energy balance Advances in geophysics 25 Elsevier Amsterdam 305353

K Didan AB Munoz R Solano A Huete 2015 MODIS vegetation index user's guide (MOD13 series) University of Arizona, Vegetation Index and Phenology Lab Tucson

El-Askary HM, Li W, El-Nadry M, Awad M, Mostafa AR (2019) Strong interactions indicated between dust aerosols and precipitation related clouds in the Nile Delta. In: El-Askary HM, Lee S, Heggy E, Pradhan B (eds) Advances in remote sensing and geo informatics applications. Springer International Publishing, Cham; pp 3-6. http://link.springer.com/10.1007/978-3-03001440-7 1. Accessed 6 Feb 2019

M El-Nadry W Li H El-Askary MA Awad AR Mostafa 2019 Urban health related air quality indicators over the Middle East and
North Africa countries using multiple satellites and AERONET data Remote Sens 112096 https://doi.org/10.3390/rs11182096

European Commission (2021) The Mediterranean Region [online]. https://ec.europa.eu/environment/nature/natura2000/biogeog_ regions/mediterranean/. Accessed 22 Feb 2020

JJ Feddema KW Oleson GB Bonan LO Mearns LE Buja GA Meehl WM Washington 2005 The importance of land-cover change in simulating future climates Science $3101674 \mathrm{https} / / / \mathrm{doi} . o r g / 10$. 1126/science. 1118160

Friedl M, Sulla-Menashe D (2015) MCD12Q1 MODIS/Terra+ aqua land cover type yearly L3 global 500m SIN grid V006. NASA EOSDIS Land Processes DAAC, vol 10

C Funk 2015 The climate hazards infrared precipitation with stations-a new environmental record for monitoring extremes Sci Data 2150066 https://doi.org/10.1038/sdata.2015.66

N Gorelick M Hancher M Dixon S Ilyushchenko D Thau R Moore 2017 Google Earth engine: planetary-scale geospatial analysis for everyone Remote Sens Environ 2021827 https://doi.org/ 10.1016/j.rse.2017.06.031

Y Jiang P Fu Q Weng 2015 Assessing the impacts of urbanizationassociated land use/cover change on land surface temperature and surface moisture: a case study in the Midwestern United States Remote Sens 748804898 https://doi.org/10.3390/rs704 04880

KM Kafi HZM Shafri ABM Shariff 2014 An analysis of LULC change detection using remotely sensed data\$mathsemicolon\$ a case study of Bauchi City IOP Conf Ser Earth Environ Sci 20012056 https://doi.org/10.1088/1755-1315/20/1/012056

P Kansara W Li H El-Askary V Lakshmi T Piechota D Struppa MA Sayed 2021 An assessment of the filling process of the grand Ethiopian Renaissance Dam and its impact on the downstream countries Remote Sens 13711 https://doi.org/10.3390/rs13040711

YH Kerr D Levine 2008 Foreword to the special issue on the soil moisture and ocean salinity (SMOS) mission IEEE Trans Geosci Remote Sens 46583585 https://doi.org/10.1109/TGRS.2008.917807

T Lasanta SM Vicente-Serrano 2012 Complex land cover change processes in semiarid Mediterranean regions: An approach using Landsat images in northeast Spain Remote Sens Environ 1241 14 https://doi.org/10.1016/j.rse.2012.04.023

J Le H El-Askary M Allali E Sayed H Sweliem T Piechota D Struppa 2020 Characterizing El Niño-Southern oscillation effects on the Blue Nile Yield and the Nile River Basin precipitation using empirical mode decomposition Earth Syst Environ 4699711 https://doi.org/10.1007/s41748-020-00192-4

J Le HM El-Askary M Allali DC Struppa 2017 Application of recurrent neural networks for drought projections in California Atmos Res 188100106

W Li 2018 An Assessment of atmospheric and meteorological factors regulating Red Sea Phytoplankton growth Remote Sens 10673 https://doi.org/10.3390/rs10050673

W Li E Ali I Abou El-Magd MM Mourad H El-Askary 2019 Studying the impact on urban health over the greater delta region in egypt due to aerosol variability using optical characteristics from satellite observations and ground-based AERONET measurements Remote Sens 111998 https://doi.org/10.3390/rs11171998

W Li H El-Askary V Lakshmi T Piechota D Struppa 2020 Earth observation and cloud computing in support of two sustainable development goals for the River Nile watershed countries Remote Sens 1291391

W Li H El-Askary K ManiKandan M Qurban M Garay O Kalashnikova 2017 Synergistic use of remote sensing and modeling to assess an anomalously high Chlorophyll-a event during summer 2015 in the South Central Red Sea Remote Sens 9778 https://doi.org/ $10.3390 / \mathrm{rs} 9080778$

W Li H El-Askary MA Qurban J Li KP ManiKandan T Piechota 2019 Using multi-indices approach to quantify mangrove changes over 
the Western Arabian Gulf along Saudi Arabia coast Ecol Ind 102 734745 https://doi.org/10.1016/j.ecolind.2019.03.047

Li W, El-Askary HM, Qurban M, Allali M, Manikandan KP (2019c) On the drying trends over the MENA countries using harmonic analysis of the enhanced vegetation index. In: El-Askary HM, Lee S, Heggy E, Pradhan B (eds) Advances in remote sensing and geo informatics applications. Springer International Publishing, Cham, pp 243-245. https://link.springer.com/10.1007/978-3-03001440-7_57. Accessed 20 Mar 2019

W Li H El-Askary R Thomas SP Tiwari KP Manikandan T Piechota D Struppa 2020 An assessment of the hydrological trends using synergistic approaches of remote sensing and model evaluations over global arid and semi-arid regions Remote Sens 12233973

SH Mahmoud AA Alazba 2015 Hydrological response to land cover changes and human activities in arid regions using a geographic information system and remote sensing PLoS ONE 10 e0125805 https://doi.org/10.1371/journal.pone.0125805

RH Maneja JD Miller W Li H El-Askary AV Flandez JJ Dagoy JF Alcaria AU Basali KA Al-Abdulkader RA Loughland MA Qurban 2020 Long-term NDVI and recent vegetation cover profiles of major offshore island nesting sites of sea turtles in Saudi waters of the northern Arabian Gulf Ecol Ind 1117106612

RH Maneja JD Miller W Li R Thomas H El-Askary S Perera AV Flandez AU Basali JF Alcaria J Gopalan S Tiwari 2020 Multidecadal analysis of beach loss at the major offshore sea turtle nesting islands in the northern Arabian Gulf Ecol Ind 8107146

McNally A, Arsenault K, Kumar S, Shukla S, Peterson P, Wang S, Funk C, Peters-Lidard CD, Verdin JP (2017) A land data assimilation system for sub-Saharan Africa food and water security applications. Sci Data. https://doi.org/10.1038/sdata.2017.12. http:// www.nature.com/articles/sdata201712. Accessed 26 Jun 2019

NASA GSFC Hydrological Sciences Laboratory (HSL) (2018) FLDAS Noah Land Surface Model L4 Global Monthly 0.1 x 0.1 degree (MERRA-2 and CHIRPS) V001. https://doi.org/10.5067/5NHC2 2T9375G. https://disc.gsfc.nasa.gov/datacollection/FLDAS_ NOAH01_C_GL_M_001.shtml. Accessed 26 Feb 2020

L Perugini L Caporaso S Marconi A Cescatti B Quesada N NobletDucoudré de JI House A Arneth 2017 Biophysical effects on temperature and precipitation due to land cover change Environ Res Lett 12053002 https://doi.org/10.1088/1748-9326/aa6b3f

RA Pielke Sr G Marland RA Betts TN Chase JL Eastman JO Niles DDS Niyogi SW Running 2002 The influence of land-use change and landscape dynamics on the climate system: relevance to climate-change policy beyond the radiative effect of greenhouse gases Philos Trans R Soc Lond Ser A Math Phys Eng Sci 360 17051719

M Rodell P Houser U Jambor J Gottschalck K Mitchell C-J Meng K Arsenault B Cosgrove J Radakovich M Bosilovich 2004 The global land data assimilation system Bull Am Meteor Soc 85381 394

SW Running Q Mu M Zhao A Moreno 2017 MODIS Global Terrestrial Evapotranspiration (ET) Product (NASA MOD16A2/A3) NASA Earth Observing System MODIS Land Algorithm NASA Washington, DC

SS Rwanga JM Ndambuki 2017 Accuracy assessment of land use/land cover classification using remote sensing and GIS Int J Geosci 08 611 https://doi.org/10.4236/ijg.2017.84033

SS Sardi MA Qurban W Li KP Kadinjappalli PK Manikandan MM Hariri BS Tawabini AB Khalil H El-Askary 2020 Assessment of areas environmentally sensitive to oil spills in the western Arabian Gulf, Saudi Arabia, for planning and undertaking an effective response Mar Pollut Bull 150110588 https://doi.org/10.1016/j. marpolbul.2019.110588

P Serra X Pons D Saurí 2008 Land-cover and land-use change in a Mediterranean landscape: a spatial analysis of driving forces integrating biophysical and human factors Appl Geogr 28189 209 https://doi.org/10.1016/j.apgeog.2008.02.001

R Sluiter 2005 Mediterranean land cover change: modelling and monitoring natural vegetation using GIS and remote sensing Koninklijk Nederlands Aardrijkskundig Genootschap, Universiteit Utrecht Utrecht

J Vargo D Habeeb B Stone 2013 The importance of land cover change across urban-rural typologies for climate modeling J Environ Manage 114243252 https://doi.org/10.1016/j.jenvman.2012.10. 007

J Verdin R Klaver 2002 Grid-cell-based crop water accounting for the famine early warning system Hydrol Process 1616171630

K Whitney E Scudiero HM El-Askary TH Skaggs M Allali DL Corwin 2018 Validating the use of MODIS time series for salinity assessment over agricultural soils in California, USA Ecol Ind 93889 898 https://doi.org/10.1016/j.ecolind.2018.05.069

Winton M (2006) Amplified Arctic climate change: what does surface albedo feedback have to do with it? Geophys Res Lett. https://doi. org/10.1029/2005GL025244. https://agupubs.onlinelibrary.wiley. com/doi/abs/10.1029/2005GL025244. Accessed 19 Jan 2021

P Xie PA Arkin 1997 Global precipitation: a 17-year monthly analysis based on gauge observations, satellite estimates, and numerical model outputs Bull Am Meteor Soc 7825392558 https://doi.org/ 10.1175/1520-0477(1997)078<2539:GPAYMA > 2.0.CO;2

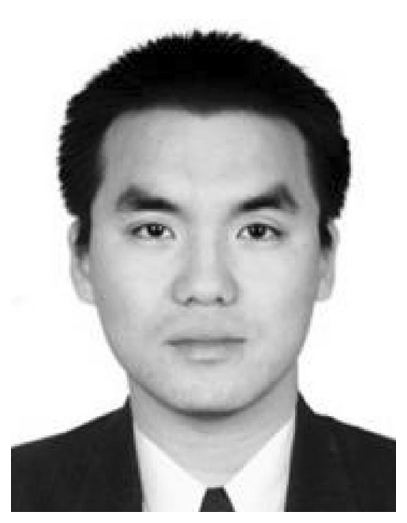

Wenzhao Li received the B.S. degree in Software and Digital Media Engineering from Shandong University, China in 2011. He received M.S. degree in Telecom and Computer Networking from Northeastern University, Boston, MA, USA in 2014. He received the $\mathrm{Ph} . \mathrm{D}$. degree in computational and data sciences at Chapman University, CA, USA in 2019. His research interests include remote sensing, oceanography, artificial intelligence and big data analysis. He has published more than 10 publications including peer-reviewed papers, full conference proceedings, and presented in international conferences such as AGU and EGU. He is a peer reviewer for several international journals such as Marine Pollution Bulletin and others.

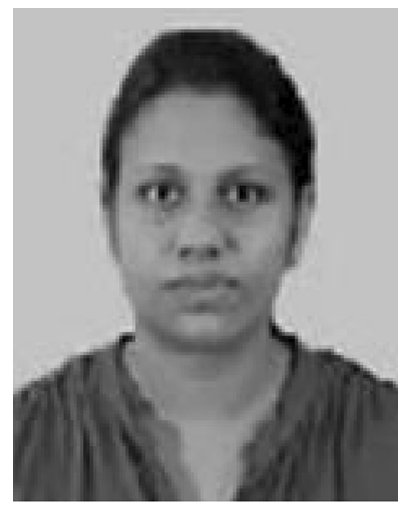

Sachi Perera received the B.Sc. degree in Statistics and Operations Research from University of Peradeniya, Sri Lanka in 2014. She received M.Sc. degree in Statistics and M.Sc. degree in Data Sciences from Michigan Technological University, MI, USA in 2018 and 2019, respectively. She is currently pursuing Ph.D. degree from Computational and Data Sciences from Chapman University, CA, USA. Her research interests include remote sensing, machine learning, image processing and vegetation, land cover and land use change studies. 


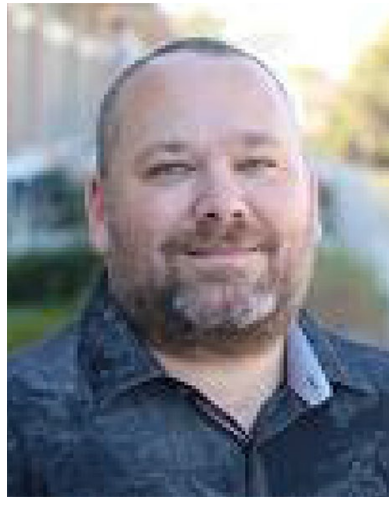

Erik Linstead received the B.S. degree in computer science from Chapman University, Orange, CA,USA, in 2001, the M.S. degree in computer science from Stanford University, Stanford, CA, USA, and the Ph.D. degree in computer science from the University of California, Irvine, CA, USA, in 2003 and2009, respectively. $\mathrm{He}$ is an Associate Professor of Computer Science and Software Engineering and Associate Dean of Academic Programs and Faculty Development with the Fowler School of Engineering, Chapman University, where he also serves as the Director of undergraduate computing programs, and is the Principal Investigator with the Machine Learning and Assistive Technology Lab. His research interests include the areas of artificial intelligence, machine learning, and information retrieval. Dr. Linstead is a Senior Member of the ACM.

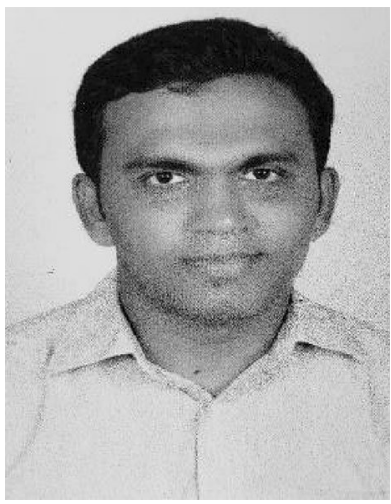

Rejoice Thomas received the B.Tech. Degree in Mechanical Engineering from Karunya University, Coimbatore, India in 2013. He received M.S. degree in Computational and Data Sciences from Chapman University, CA, USA in 2020 . He is currently pursuing $\mathrm{Ph} . \mathrm{D}$. degree from Computational and Data Sciences from Chapman University, CA, USA. His research interests include remote sensing, crop prediction, transfer learning, machine learning and drought monitoring.

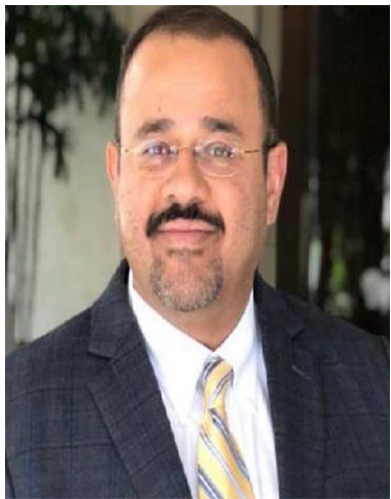

Hesham El-Askary received the B.S. degree in Physics with focus on Geophysics from Alexandria University, Alexandria, Egypt, in 1994. He received his two M.S. degrees in Earth Systems Science and Computational Science and Informatics as well as his Ph.D. with focus on Environmental Physics, from George Mason University, Virginia, USA, in 2003 and 2004, respectively. Since 2008 , he has been with the Schmid College of Science and Technology, Chapman University, CA, USA and is currently a Professor of Earth Systems Science and Remote Sensing and serves as the program director for the Computational and Data Sciences graduate program, Chapman University, CA, USA. He also holds a Full Professor position at Faculty of Science, Alexandria University, Egypt (on leave). His research interests include modeling and observations of earth systems' processes with focus on natural disasters. He has published more than 100 publications including peer-reviewed papers, book chapters, full conference proceedings and other conference papers. He is a peer reviewer for several international journals such as atmospheric chemistry and physics, remote sensing, IEEE transaction on geosciences and remote sensing and others. NASA, USDA, NSF and EU have funded his work.

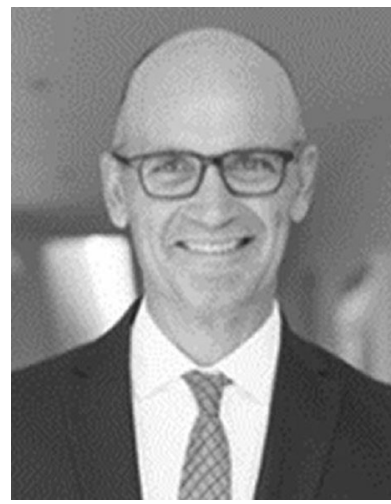

Thomas Piechota received the B.S. in Civil Engineering in 1989 from Northern Arizona University, his M.S. in Civil and Environmental Engineering in 1993 from UCLA, and his Ph.D. in Civil and Environmental Engineering in 1997 from UCLA. Dr. Piechota has been recognized for his efforts in teaching, research and as an administrator where he has helped advance the research enterprise through increases in research funding, outside partnerships and entrepreneurial activities. Dr. Piechota is the Vice President for Research and Professor of Environmental Science and Policy at Chapman University since 2016. In 2003, Dr. Piechota received a National Science Foundation CAREER Award for the project, "Improved Hydrologic Drought Forecasting Using Climate Information." From 2008-2013, Dr. Piechota was the Co-PI on a \$20 million National Science Foundation funded studies on climate change impacts in Nevada. Dr. Piechota was an invited Lead Author on the Southwest Chapter of the National Climate Assessment in 2013. Finally, Dr. Piechota was part of the 2013 Solar Decathlon team that took second place in world competition and first in the U.S. He has authored or coauthored more than 100 journal articles, book chapters, conference proceedings, and reports, and his work has been cited more than 3000 times. Dr. Piechota is a licensed Professional Engineer in the California. He has served on review panels for the National Science Foundation and various federal agencies. He has served on various professional and community committees including the American Society of Civil Engineers.

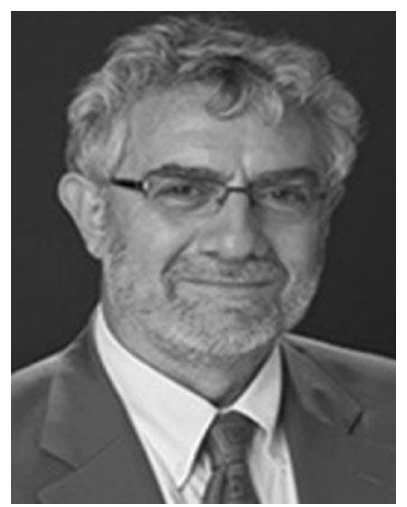

Daniele Struppa received the B.S. degree in Mathematics from the University of Milano, Italy, in 1977. He received his Ph.D. in Mathematics from the University of Maryland, College Park, in 1981, with a dissertation on exponential representations for solutions of systems of convolution equations. He has been an Assistant Professor at the University of Milano (1981-1984), at the Scuola Normale Superiore in Pisa (1984-1987), and then a Full Professor of Mathematics at the University of Calabria (1987-1994), at George Mason University (1988 2006), and now at Chapman University since 2006. He is currently the President of Chapman University, where he also holds The Donald Bren Distinguished Presidential Chair in Mathematics. He has published more than 200 publications including several books, edited books, peer reviewed papers, book chapters, full conference proceedings and other conference papers. A paper he coauthored in 2016 received the Cozzarelli Prize from the National Academy of Sciences. Dr. Struppa is a managing editor for Quantum Studies: Mathematics and Foundations, and for the Hypercomplex section of Complex Analysis: Operator Theory. He a reviewer for several international journals and his work has been funded by NATO, NSF and EU. 